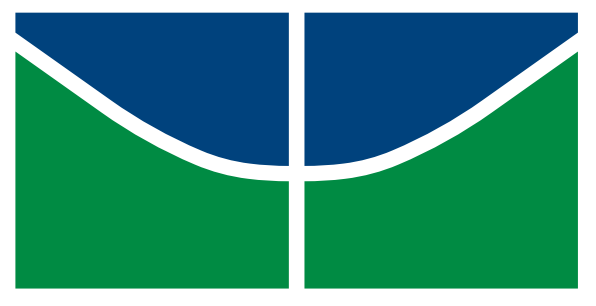

Universidade de Brasília

Instituto de Ciências Biológicas

Programa de Pós-Graduação em Ecologia

\title{
Biogeografia e Conservação dos Anfíbios da Caatinga
}

Mariana Garcez Stein

Brasília - DF

2015 
Universidade de Brasília

Instituto de Ciências Biológicas

Programa de Pós-Graduação em Ecologia

\title{
Biogeografia e Conservação dos Anfíbios da Caatinga
}

\author{
Mariana Garcez Stein
}

Orientador: Prof. Dr. Ricardo Bomfim Machado

Coorientador: Prof. Dr. Adrian Antônio Garda

Dissertação apresentada ao Programa de Pós-Graduação em Ecologia da Universidade de Brasília como parte dos requisitos necessários para a obtenção do título de Mestre em Ecologia.

Brasília - DF

2015 


\title{
$\Psi$
}

Universidade de Brasilia

Instituto de Ciências Biológicas

Programa de Pós-Graduação em Ecologia

\author{
Dissertação de Mestrado
}

\section{Mariana Garcez Stein}

Título:

"Biogeografia e Conservação dos Anfíbios da Caatinga"

\author{
Banca Examinadora:
}

$$
\begin{gathered}
\text { Prof. Df. Ricardo Bomlinf Machado } \\
\text { Presidente/Orientador } \\
\text { ECL/UnB }
\end{gathered}
$$

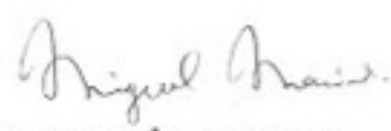

Prof. Dr. Miguel Angelo Marini Membro Titular $\mathrm{ZOO} / \mathrm{UnB}$

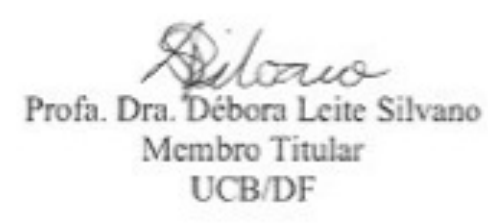

Prof. Dr. Ludgero Cardoso Galli Vicira

Membro Suplente

UnB/FUP 
À minha amada família. 


\section{Agradecimentos}

Agradeço a todos que contribuíram, direta ou indiretamente, para a realização deste trabalho. Desde a graduação foram diversos professores, colegas e amigos que dividiram comigo não apenas conhecimento e informações, mas uma forma de ver o mundo. Ao longo desses anos foi enorme o apoio que recebi não apenas no meio acadêmico, mas de todos que me cercam. Obrigada a Todos!

Agradeço ao Cnpq pela bolsa de estudos fornecida.

Agradeço ao Pacheco que aceitou me orientar sem me conhecer direito e mesmo sabendo que eu não tinha a menor experiência na área e no projeto que íamos desenvolver. Ao meu coorientador Adrian que aceitou nos ajudar, pois os anfíbios e a Caatinga também eram uma "novidade" para mim.

Aos meus queridos colegas de turma que fizeram desta jornada mais divertida, em especial a Tânia e Débora, que são desesperadas como eu, sinto saudade dos nossos domingos de estudos na salinha da pós. E claro, Daniel que sempre falava que "Vocês estudam demais!". Vocês três foram fundamentais.

Agradeço ao colegas do LaBio (onde não é permitida a entrada de pessoas estranhas e esquisitas) que sempre estiveram dispostos a me ajudar e dar todo apoio quando os resultados davam estranho, quando eu estava perdida, ou quando eu desanimava. Babi, Tatá, Thalita, Renatinha, Vivian, Romina, Giovana, Reile, Yuri e Danilo. Renata Françoso (Tatá) obrigada por me ajudar com as análises de agrupamento.

Vivian obrigada por me ajudar tanto nesse trabalho, nem sei como agradecer. Vivian e Renatinho obrigada por compartilharem tantos momentos e informações comigo, inclusive e principalmente o desespero.

Aos amigos feitos durante essa caminhada, desde a época de EcoCampo (Ana Hermínia, Leo, Pamela, Almir, Geraldinho, Sú.... ) quando eu era uma aluna especial da ecologia, aos amigos de corredores e disciplinas. Ao amigo Samuel que me fez companhia na nossa vida de "coruja". Aos companheiros de Ubajara, Sarah Mângia, Taís Costa, Daniel Orsi, Deborah Praciano, Ricardo Rodrigues pela companhia e por compartilharem informações comigo. 
Aos amigos de uma vida inteira, minha família Cheetos (Anninha, Natália, Iza, Will, Bob, Renata, Samir) sempre me dando muito apoio e carinho. Aos queridos Paty, Paulista e Denise sempre presentes. Aos $2 \%$, a turma mais sucesso da biologia. A todos os amigos que conquistei ao longo desses anos.

Agradeço ao Thiago, carinhosamente apelidado de Pará, pelo companheirismo, carinho e principalmente pela paciência nesses quase dois anos.

Agradeço especialmente a minha família por todo apoio dado não só no mestrado, mas durante toda a vida. Minha mãe Carla e meu pai Jorge que sempre fizeram todo possível pra que eu realizasse meus sonhos, as minhas irmãs Luana, Juliana e Alana, que me apoiam em tudo. Obrigada por tudo e desculpem as eventuais ausências e o estresse constante. Amo vocês!

Foram longos "dois" anos, mas passaram num piscar de olhos. Foram muitos artigos, muitos pontos, alguns softwares, centenas de mapas, muitos finais de semana, 12 quilos, muitas lágrimas, muitas muitas muitas unhas roídas e algumas dancinhas de comemoração. Aprendi muita coisa durante esses anos. Agradeço a todos, principalmente a todas as vezes que ouvi "Calma Mari! Vai dar certo!”. 


\section{Sumário}

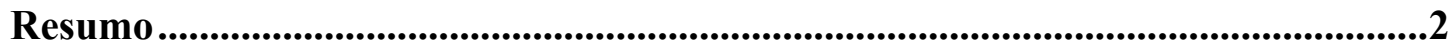

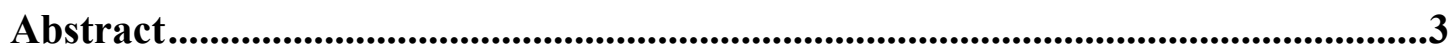

Introduçãa

Materiais e Métodos.............................................................................................................8

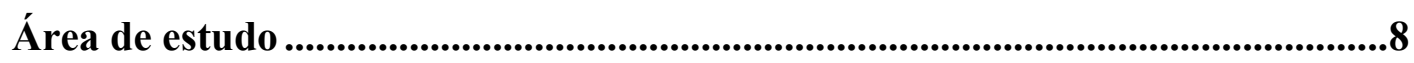

Seleção de espécies e coleta de dados......................................................................9

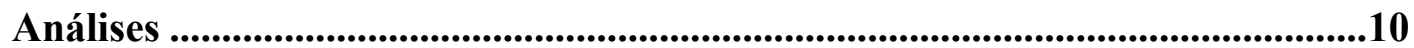

Modelagem da distribuição das espécies - SDM (Species Distribution Modeling)

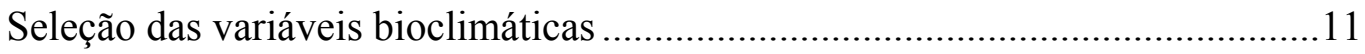

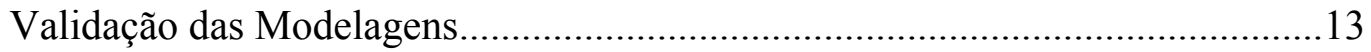

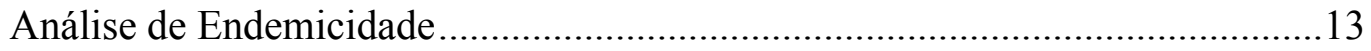

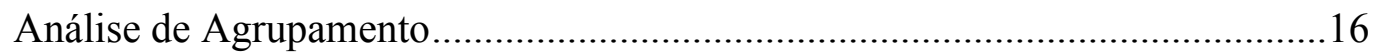

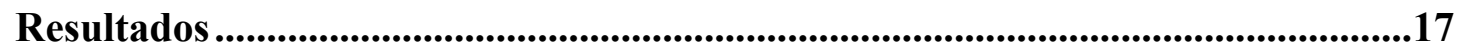

Análise de endemicidade ........................................................................18

Análise de Agrupamento ....................................................................................23

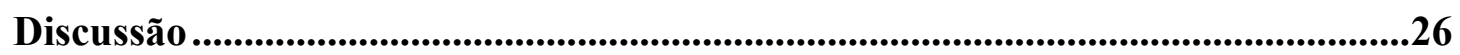

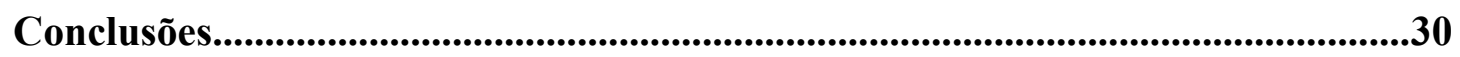

Referências Bibliográficas.........................................................................32

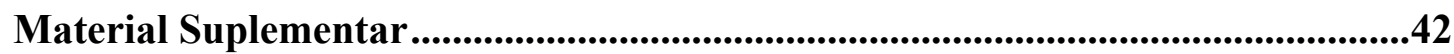




\section{Resumo}

A busca por padrões de distribuição dos organismos é uma das questões centrais da biologia. A Biogeografia é a ciência que busca identificar esses padrões assim como os processos que levaram a formação dos mesmos. A Caatinga é único bioma exclusivamente brasileiro e embora historicamente descrito como homogêneo e sem biota própria, atualmente sabe-se que é um bioma heterogêneo e que apresenta regiões de elevado endemismo. Apesar disso, trata-se do bioma menos estudado e conservado do país. Este trabalho teve como objetivo identificar e compreender os padrões de distribuição dos anuros na Caatinga, utilizando ferramentas de modelagem de distribuição de espécies, análise de endemicidade e análise de agrupamento. Os resultados mostraram que há uma de escassez de informações sobre a distribuição geográfica dos organismos. Apesar disso, elevadas áreas de riqueza foram encontradas e se localizaram principalmente na região leste do bioma e na Chapada Diamantina. Entre as áreas de endemismo obtidas no estudo destacam-se a área referente a Caatinga e outra localizada na Chapada Diamantina. A Caatinga mostra-se ainda como um bioma heterogêneo, dividido em seis grupos pela análise de agrupamento. Os grupos obtidos se mostraram distintos da divisão da Caatinga em ecorregiões. Assim, estudos de conservação de anfíbios no bioma não devem ser baseados na divisão do bioma em ecorregiões, pois as mesmas não representam a distribuição dos anfíbios no bioma.

Palavras-chave: ecorregiões, endemismo, modelagem de distribuição de espécies. 


\begin{abstract}
The search for organism distribution patterns is one of the central questions in biology studies. The science that seeks to identify these patterns, as well as the processes that led to them, is called Biogeography. Caatinga is the only exclusively Brazilian biome and, although historically described as homogeneous and without unique biota, it is now considered a heterogeneous biome, with high endemism regions. Nevertheless, it is the least studied and conserved biome in the country. This study aimed to identify and understand the distribution patterns of anurans in Caatinga, using species distribution modeling, endemicity, and cluster analysis. The results showed that there is a scarcity of information on the geographical distribution of organisms. However, we found high richness areas, located mainly in the eastern part of the biome and in Chapada Diamantina region. Among the endemism areas observed in this study, both the area regarding the entire biome and the one located in Chapada Diamantina stood out. We also perceived that Caatinga is a heterogeneous biome, divided into six groups by cluster analysis. The obtained groups were distinct from the ecoregions suggested as a division of Caatinga. Therefore, amphibian studies and actions for their conservation in the biome should not be based on classical division in ecoregions, because they do not represent the real distribution of amphibians in the biome.
\end{abstract}

Keywords: ecoregions, endemism, species distribution modeling. 


\section{Introdução}

Os organismos vivos não estão distribuídos de maneira aleatória e a riqueza de espécies é heterogeneamente distribuída no globo terrestre (Gaston, 2000; Sclater, 1858). Diferentes padrões de distribuição já foram identificados para plantas e animais, desde a escala global até níveis regionais. Sabe-se que os padrões atuais de distribuição dos organismos são resultantes da interação de fatores históricos e fatores ecológicos (Brown \& Lomolino, 2006). Alguns padrões são amplamente conhecidos, como o gradiente latitudinal de riqueza de espécies, um dos padrões globais de distribuição da diversidade (Fischer, 1960; Gaston, 2000). Ainda assim, a busca por padrões e as explicações para os mesmos permanece como uma das questões centrais na biologia.

A Biogeografia é a ciência que tem como princípio identificar os padrões de distribuição dos organismos, assim como avaliar os processos ou eventos que levaram e levam à sua formação (Brown \& Lomolino, 2006; Crisci et al., 2006). Trata-se de uma área de estudo multidisciplinar que utiliza princípios da Geografia, da Ecologia, da Biologia Sistemática e da Geologia. Esta ciência, ao longo do seu desenvolvimento, foi tradicionalmente dividida em duas abordagens distintas: a Biogeografia Histórica e a Biogeografia Ecológica. A primeira delas procura explicar os padrões biogeográficos e as distribuições atuais dos organismos com base em eventos ocorridos no passado, alinhando as hipóteses com a história geológica. A segunda abordagem procura explicar os padrões com base nas interações ecológicas que influenciam a distribuição dos organismos (Brown \& Lomolino, 2006; Wiens \& Donoghue, 2004). Atualmente diferentes pesquisadores acreditam que a integração entre ambas as abordagens é fundamental para responder as questões de Biogeografia (Crisci et al., 2006; Wiens \& Donoghue, 2004). Embora seja uma disciplina antiga, o estudo da Biogeografia expandiu apenas nas últimas décadas devido ao desenvolvimento de tecnologias de coleta de dados e monitoramento de áreas por satélite, assim como enorme avanço da tecnologia computacional, incluindo o desenvolvimento de novos programas e aplicativos. Esses avanços permitem explorar novas abordagens dentro desta área de estudo, devido ao aumento qualitativo e quantitativo de dados, assim como o desenvolvimento de ferramentas que permitem análises mais apropriadas (Brown \& Lomolino, 2006). 
Independente da abordagem, Histórica ou Ecológica, a distribuição das espécies é uma informação fundamental no estudo da Biogeografia. No entanto, para grande parte das espécies não se tem conhecimento adequado sobre suas distribuições geográficas, existindo muitas lacunas de conhecimento. Tal deficiência de informação acerca da distribuição global, regional e local de diferentes táxons foi nomeada de “déficit wallaceano" (Escalante et al., 2009; Giannini et al., 2012; De Marco Júnior \& Siqueira, 2009; Lomolino, 2004). Os modelos de distribuição potencial de espécies têm sido uma ferramenta importante para auxiliar na formulação de hipóteses sobre a distribuição esperada dos organismos, principalmente nos casos de espécies raras ou que possuem pouca informação acerca de sua ocorrência no tempo e no espaço (Guisan \& Zimmermann, 2000).

A modelagem de distribuição de espécies, também denominada como modelagem de nicho ecológico (Peterson, 2001), é utilizada para diferentes fins como avaliar a perda de diversidade (Polasky \& Solo, 2001), o impacto de mudanças climáticas (Peterson et al., 2002; Siqueira \& Peterson, 2003), ou para auxiliar a determinação de áreas prioritárias (Ortega-Huerta \& Peterson, 2004).

Diferentes ferramentas da Biogeografia também têm sido utilizadas na delimitação de estratégias de conservação, no âmbito da Biogeografia da Conservação, que utiliza análises e princípios biogeográficos de distribuição de espécies para solucionar questões da Biologia da Conservação (Posadas et al., 2006; Whittaker et al., 2005). Dentre as análises mais utilizadas podemos destacar o estudo de áreas de endemismo, que são áreas nas quais encontram-se similaridades de distribuição geográfica entre espécies (Platnick, 1991; DaSilva, 2011) e muitas vezes são utilizadas para apontar áreas prioritárias para conservação (Camardelli \& Napoli, 2012; Guedes et al., 2014a). Para algumas trabalhos, as áreas de endemismo foram encontradas relacionadas à áreas de elevada riqueza (Camardelli \& Napoli, 2012).

Existem ainda, diferentes métodos para avaliar a estrutura espacial de populações e comunidades (Legendre \& Fortin, 1989). Considerando a composição das espécies em uma região, as análises de agrupamento (Cluster Analysis) podem ser empregadas para diferenciação de sub-regiões com base nas diferenças e similaridades encontradas.

Historicamente, a Caatinga foi negligenciada no que diz respeito à sua 
biodiversidade, acreditava-se tratar de um bioma homogêneo, de baixa riqueza e endemismos (Vanzolini, 1976). No entanto, recentes estudos mostram que a Caatinga é o um bioma bastante heterogêneo (Guedes et al., 2014a) e propostas de subdivisão do bioma já foram elaboradas. Por exemplo, Velloso et al. (2002) propuseram a existência de oito ecorregiões (sensu Bailey, 1998) distintas. Ecorregiões são definidas como unidades geográficas que destinam-se principalmente à conservação, são delimitadas por fatores bióticos e abióticos, que supostamente refletem a distribuição das espécies na paisagem (Olson \& Dinnerstein, 1998; Olson et al., 2001). Uma outra indicação da singularidade das espécies associadas à Caatinga é o número de endemismos reconhecidos. O nível de endemismo varia entre táxons, podendo ser entre 3\%, registrado para aves, até $57 \%$ registrado para peixes (MMA, 2002). Algumas regiões dentro do bioma podem apresentar elevado endemismo, como a região de dunas do rio São Francisco, onde 40\% das espécies de lagartos e anfisbenas são endêmicas da região (Rodrigues, 1996).

Embora atualmente tenha-se o conhecimento que o bioma apresenta espécies endêmicas, e não apenas não apenas provenientes dos biomas adjacentes, pouca atenção tem sido voltada para seu estudo e conservação. É um dos biomas brasileiros mais degradados e alterados, onde mais de $68 \%$ de sua área apresenta algum grau de antropizacão (MMA, 2002). A região continua sendo amplamente impactada por atividades de agropecuária e extrativismo (Giulietti et al., 2004), o que tem levado à formação de núcleos de desertificação, que por seguinte geram uma perda de diversidade ainda não mensurada (Camardelli \& Napoli, 2012; DaSilva et al., 2004). Embora seja o único bioma exclusivamente brasileiro, apenas 1\% de seu território encontra-se protegido por unidades de conservação de proteção integral (Leal et al., 2005), sendo dos biomas brasileiros o menos protegido (MMA 2004; Silva et al., 2004).

Como resultado de um processo de compilação de informações técnicas e consultas a especialistas, foram identificadas 82 áreas prioritárias para conservação da biodiversidade na Caatinga (MMA, 2007). Posteriormente, um estudo sobre a anurofauna da região semiárida e do bioma Caatinga apontou a existência de 15 áreas prioritárias para a conservação dos anfíbios (Camardelli \& Napoli, 2012). Tais áreas são equivalentes àquelas apontadas no trabalho de áreas prioritárias para conservação da biodiversidade na Caatinga (MMA, 2007). No entanto, estima-se que $40 \%$ da 
área da Caatinga não tenha sido amostrada e que grande parte do bioma seja subamostrado (Tabarelli \& Silva, 2003; Tabarelli \& Vicente, 2003).

Os anfíbios estão entre os vertebrados mais ameaçados do planeta (Hoffman et al., 2010), nas últimas décadas foram registradas declínios populacionais e extinções de espécies ao redor do mundo (Young et al., 2001). No Brasil, o conhecimento sobre o declínio populacional dos anfíbios é bastante escasso, muito devido a falta de estudos da biologia das espécies, assim como monitoramentos a longo prazo do grupo (Silvano \& Segalla, 2005). Sabendo que a disponibilidade de água e a temperatura são fatores que restringem a distribuição dos anfíbios (Buckley \& Jetz, 2007), acredita-se que mudanças climáticas globais afetarão e ameaçarão ainda mais a conservação do taxa, o que torna clara a necessidade de traçar planos de conservação para o grupo.

Atualmente 6.488 espécies de anfíbios anuros estão descritas globalmente (Frost, 2015) e 988 delas (15,2\%) são encontradas no Brasil (SBH, 2014). De acordo com Rodrigues (2003) 48 espécies de anuros foram registradas no bioma Caatinga, Camardelli \& Napoli (2012) registram 107 espécies para a região do semiárido brasileiro e dessas 73 espécies encontradas na Caatinga. No entanto, o conhecimento acerca da diversidade de anuros na Caatinga ainda se mostra escasso. Nos últimos anos, dezenas de novos registros de distribuição dos anuros foram realizados e mais de 13 espécies novas foram descritas para o bioma (Caramaschi, 2006; Carvalho et al., 2013; Cassimiro et al., 2008; Cruz et al. 2012 Faivovich et al., 2009; Lugli \& Haddad, 2006a, 2006b; Maciel \& Nunes, 2010; Magalhães et al., 2014; Napoli \& Juncá, 2006; Napoli et al., 2011; Pombal et al., 2012). Diferentes trabalhos apontam que a riqueza em alguns locais pode ser superior ao conhecido e que dada a imprevisibilidade de chuvas na região, que dificulta o levantamento nesses períodos, diversas regiões no bioma são subamostradas para o esse grupo (Garda et al,. 2013; Rodrigues, 2003).

Deste modo, realizou-se neste trabalho um levantamento bibliográfico sobre a distribuição das espécies de anfíbios anuros identificadas no bioma Caatinga, tendo como objetivos: estimar a riqueza potencial do taxa no bioma; identificar os padrões biogeográficos dos anfíbios na Caatinga pela identificação de áreas de endemismo, assim como pela delimitação de grupos ecológicos com base na análise de agrupamento; e verificar se a proposta da divisão da Caatinga em oito ecorregiões é 
suportada por estes padrões biogeográficos. Para tanto, foram construídos mapas de distribuição potencial das espécies, sendo os mesmos utilizados em uma análise voltada para a identificação de eventuais congruências com as ecorregiões.

\section{Materiais e Métodos}

\section{$\underline{\text { Área de estudo }}$}

O estudo abrangeu o bioma da Caatinga e o limite utilizado correspondeu a uma combinação do mapa oficial dos biomas do Brasil (IBGE, 2004) com o das ecorregiões definidas por Velloso et al. (2002) (Figura 1). Juntamente com o Cerrado e o Chaco argentino, a Caatinga, que possui uma área de $734.478 \mathrm{~km}^{2}$, faz parte da chamada diagonal de formações abertas da América do Sul (Vanzolini 1963, 1974). A Caatinga é caracterizada por um clima quente e semiárido, com baixa precipitação, que ocorre de maneira irregular e em um curto período de tempo, não sendo incomum algumas regiões ficarem anos sem chuva. O bioma se apresenta como um mosaico de diferentes tipos de vegetação que variam de acordo com os tipos de solo e a disponibilidade de água. O relevo da região é relativamente diverso e com uma variada história nas diferentes formações geológicas, apresentando regiões de depressão como a Depressão Cearense e planaltos como a Chapada do Araripe (Prado, 2003; Velloso et al., 2002).

A partir dessa diversidade de mosaicos de relevos, solos, ambientes e com intuito de entender como estão dispostos, foi proposta a divisão deste bioma em ecorregiões. De acordo com trabalho de Velloso et al. (2002), ecorregião é definida “uma unidade relativamente grande de terra e água delineada pelos fatores bióticos e abióticos que regulam a estrutura e função das comunidades naturais que lá se encontram" (Bailey, 1998). Desta maneira, foram sugeridas oito ecorregiões pra a Caatinga: o Complexo Campo Maior, o Complexo Ibiapaba-Araripe, a Depressão Sertaneja Setentrional, o Planalto da Borborema, a Depressão Sertaneja Meridional, as Dunas do São Francisco, o Complexo da Chapada Diamantina e o Raso da Catarina (Velloso et al., 2002, Figura 1B). Os enclaves de floresta úmida, frequentemente referidos como brejos de altitude, não foram incluídos no trabalho de Velloso et al. 
(2002) devido à maior afinidade dos mesmos com os biomas florestais, como Mata Atlântica e Amazônia (Andrade-Lima, 1981).

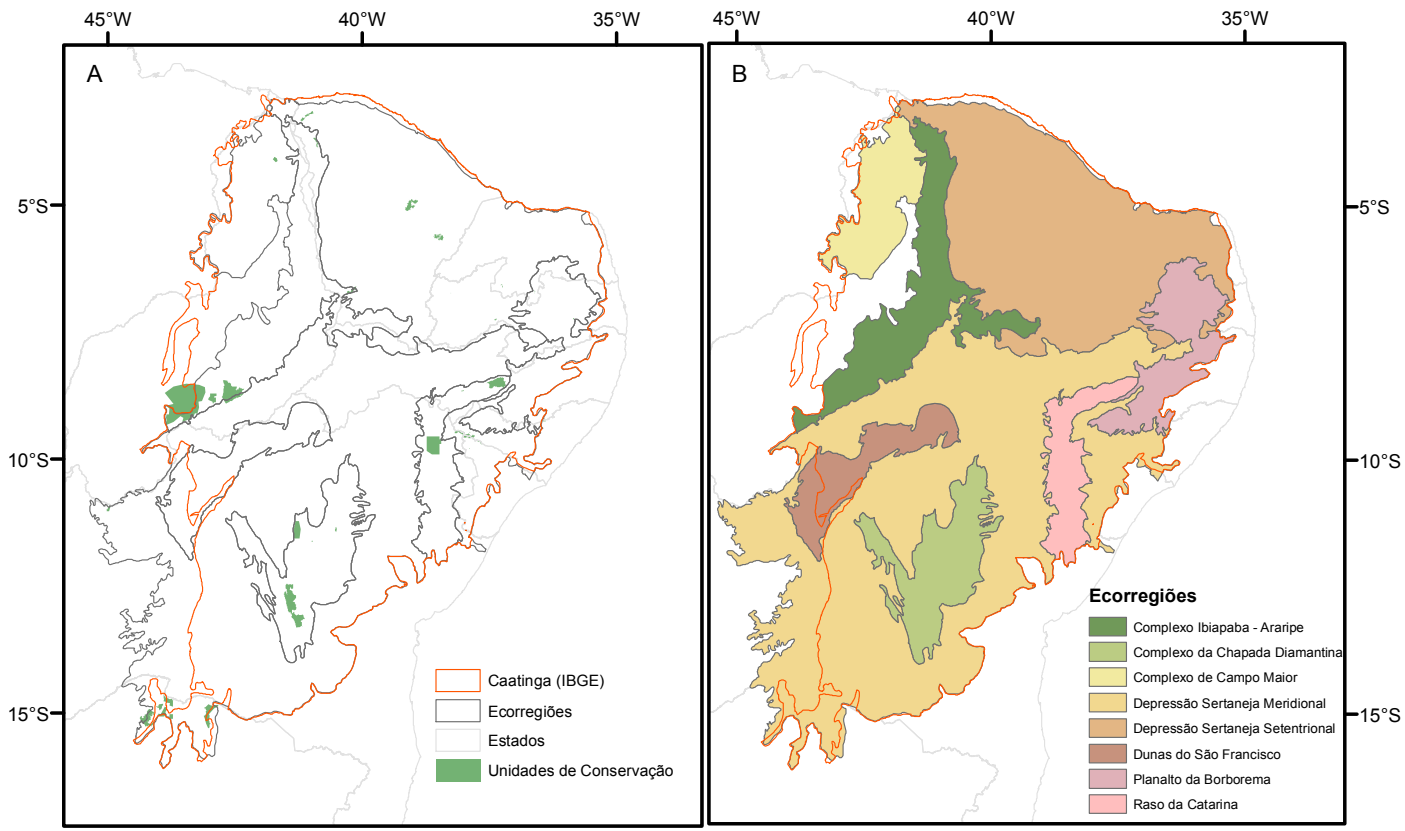

Figura 1. Área de estudo. A) Limites da Caatinga (IBGE, 2004) e ecorregiões (Velloso et al., 2002), além das Unidades de Conservação de Proteção Integral existentes no bioma, representadas em verde; B) As ecorregiões propostas por Velloso et al. (2002).

\section{Seleção de espécies e coleta de dados}

As espécies que apresentaram ao menos um ponto de ocorrência dentro dos limites da Caatinga (IBGE, 2004) e ecorregiões (Velloso et al., 2002) foram selecionadas para as análises, com exceção das espécies endêmicas dos encraves de floresta úmida. Esta seleção foi realizada com base em dados prévios acerca da distribuição das mesmas, obtidos na literatura. Apenas espécies formalmente descritas e com ausência de confusões taxonômicas foram utilizadas no trabalho. A taxonomia adotada neste trabalho segue aquela proposta por Frost (2015).

Os dados de distribuição geográfica das espécies foram obtidos de uma extensa revisão na literatura cientifica, levantamento de dados existentes na chamada literatura cinza, assim como a utilização de informações da plataforma Global Biodiversity Information Facility - GBIF (http://www.gbif.org), que 
disponibiliza dados georreferenciados de espécimes depositados em coleções científicas. O levantamento foi complementado com uma pesquisa realizada na plataforma SpeciesLink (http://splink.cria.org.br).

No estudo foram selecionados apenas os dados que apresentavam georeferenciamento e os mesmos foram plotados para verificar a precisão de sua localização e congruência com mapas de distribuição conhecidos. Desta forma, procurou-se diminuir a existência possíveis erros de localização das ocorrências das espécies.

O trabalho foi desenvolvido com 65 espécies de anfíbios anuros e elas foram agrupadas conforme o padrão de distribuição. Foram criados dois grupos, um denominado 'espécie restrita' que abrangeu espécies que apresentaram ao menos $80 \%$ dos pontos de ocorrência dentro dos limites $25^{\circ}-45^{\circ}$ Oeste e $2^{\circ}-18^{\circ}$ Sul e as demais colocadas no grupo 'espécie amplas' (Tabela S1). Entre as 65 espécies selecionadas, 18 são espécies descritas como endêmicas do bioma, ou ainda endêmicas da região da Chapada da Diamantina.

Para visualizar a distribuição dos dados de ocorrência das espécies, dividiu-se a Caatinga em quadrículas de $0,5^{\circ} \times 0,5^{\circ}$, contabilizando então o número de espécies presentes em cada quadrícula utilizando apenas os pontos de ocorrência das espécies. O mapa foi produzido no programa ArcGis v10 (ESRI, 2010).

\section{Análises}

Modelagem da distribuição das espécies - SDM (Species Distribution Modeling)

Foram selecionadas para esta análise as espécies que apresentavam ao menos nove pontos de ocorrência únicos (seguindo os procedimentos dados por Wisz et al. (2008), considerando a resolução espacial da base de dados climáticos utilizada (aproximadamente $5 \times 5 \mathrm{~km}$ ). Os pontos foram divididos em dois conjuntos, sendo um para treino (utilizados para a produção dos modelos de distribuição potencial) e outro para teste (utilizados para avaliação dos modelos) (Tabela S1). A seleção dos pontos foi aleatória, $70 \%$ dos pontos destinados para treino e o restante $(30 \%)$ para teste. A seleção foi feita com o uso da extensão Hawth's analyses tools (Beyer, 2004) do programa ArcGis v10 (ESRI, 2010). 
Para cada espécie de anuro com os pontos mínimos, construiu-se um modelo de distribuição potencial utilizando o algoritmo de Máxima Entropia - Maxent (Phillips et al., 2006). A utilização deste algoritmo para modelagem de distribuição de espécies tem sido extensiva e para diversas finalidades entre aplicações ecológicas, evolutivas, conservacionistas e de biossegurança (Elith et al., 2011). A escolha deste algoritmo foi devido ao desempenho superior quando comparado a outros algoritmos, para análises com poucos pontos de ocorrência (Wisz et al., 2008) e devido ao fato apresentar bons resultados de modelagem quando, como no presente estudo, são utilizados apenas dados de presença (Phillips et al., 2006; Elith \& Graham, 2009).

Para cada espécie foram feitas 15 réplicas de modelos e o modelo de consenso representou o modelo médio das réplicas produzidas. Foi utilizado o método boostrap para a produção das réplicas. O procedimento é feito pelo próprio Maxent, onde todos os pontos de ocorrência de uma espécie são utilizados para geração das réplicas de modelo e também para os testes internos. Os valores de adequabilidade ambiental dos modelos médios foram reclassificados de acordo com um limite de corte (threshold) para produzir mapas binários ( 0 para ausência, 1 para presença potencial). Para tanto, foi escolhido o parâmetro Max SSS - Maximum training sensitivity plus specificity, por ser o mais indicado em dados de apenas presença (Liu et al., 2013). Para as análises biogeográficas descritas a seguir, utilizaram-se apenas os mapas binários.

Para as espécies que não apresentaram o mínimo de pontos para as modelagens de distribuição potencial, ou quando os modelos propostos não foram considerados válidos pela análise parcial do ROC (Receiver Operating Characteristic), utilizou-se os mapas de distribuição das espécies de anfíbios (disponibilizados pela União Internacional para Conservação da Natureza - IUCN) como mapas binários, ou ainda mapas fornecidos por especialista. Quando os mapas na forma de polígonos não se encontravam disponíveis, que foi o caso de espécies com apenas um ou dois pontos de ocorrência, foi gerado um buffer de $10 \mathrm{~km}$ ao redor dos mesmos. Os shapes e buffers foram transformados em mapas binários para as análises subsequentes.

\section{Seleção das variáveis bioclimáticas}

As variáveis bioclimáticas utilizadas na modelagem de distribuição das espécies foram obtidas na Base de WorldClim, na resolução 2,5 arcos de minuto 
(aproximadamente $5 \times 5 \mathrm{~km}$ ), para o ano de 2000 (Hijmans et al., 2005, www.worldclim.org). Posteriormente foram selecionadas apenas as variáveis que não apresentaram correlação igual ou maior a $90 \%(r=0,9)$. As análises de correlações foram realizadas no programa $\mathrm{R}$ ( $\mathrm{R}$ Development Core Team, 2014)

Para tanto duas seleções distintas das variáveis ambientais foram realizadas, sendo uma para as espécies de distribuição restrita e outra para espécies de distribuição ampla. Optou-se pela realização de duas análises tendo em vista que a correlação entre as variáveis é distinta dependendo da área que esta sendo estudada. Desta forma, realizou-se uma análise de correlação das variáveis para as espécies restritas tendo como limite geográfico $2^{\circ}-18^{\circ}$ Lat $\mathrm{S}$ e $35^{\circ}-49^{\circ}$ Long W. Na análise de correlação das variáveis para as espécies de ampla distribuição foram utilizados os limites de $53^{\circ}$ Lat $\mathrm{S} \mathrm{a} 3^{\circ}$ Lat $\mathrm{N}$ e $35^{\circ}$ a $65^{\circ}$ Long $\mathrm{W}$.

Tabela 1 - Variáveis ambientais do WorldClim não correlacionadas e usadas para gerar os modelos de distribuição das espécies. (*Variável selecionada apenas para espécies de distribuição restrita; ** Variáveis selecionadas apenas para espécies de distribuição ampla).

\begin{tabular}{ll}
\hline Variável Ambiental & \multicolumn{1}{c}{ Descrição } \\
\hline BIO 1 & Temperatura Média Anual \\
BIO 2 & Variação da Temperatura média diurna \\
BIO 3 & Isotermalidade \\
BIO 4 & Sazonalidade da Temperatura \\
BIO $5^{*}$ & Temperatura máxima no mês mais quente \\
BIO $6^{*}$ & Temperatura mínima no mês mais frio \\
BIO $7^{* *}$ & Faixa de temperatura anual \\
BIO 12 & Precipitação Anual \\
BIO 13 & Precipitação do mês mais úmido \\
BIO 14 & Precipitação do mês mais seco \\
BIO 15 & Sazonalidade de precipitação (Coeficiente de Variação) \\
Altitude & Altitude \\
Vegetação & MODIS Vegetation Continuous Fields \\
\hline
\end{tabular}

Ao todo foram selecionadas 11 das 19 variáveis ambientais disponíveis na base do WorldClim (Tabela 1), acrescentadas de altitude e MODIS Vegetation Continuous Fields - VCF. O VCF é uma imagem de satélite produzida pelo sensor 
MODIS (Moderate Resolution Imaging Spectroradiometer) que está a bordo dos satélites Terra e Aqua. Os valores contidos no VCF utilizado, datado do ano de 2010, representam a cobertura vegetal em uma escala de 0 (área sem vegetação) a 1 (área coberta por floresta).

\section{Validação dos Modelos}

Para avaliar a qualidade dos modelos de distribuição obtidos, utilizou-se a avaliação parcial do ROC (Peterson et al., 2008). A análise do ROC parcial avalia os erros de comissão e omissão do modelo, em uma área menor que na análise do ROC tradicional, uma área de maior correspondência com a área do modelo, diminuindo assim a taxa de ausências corretamente preditas pelo modelo. Para esta análise foi utilizado o programa partial ROC (Peterson, 2012), que avalia se os modelos gerados apresentam performance melhor que a distribuição randômica. O software partial $R O C$ esta disponível no site http://kuscholarworks.ku.edu/handle/1808/10059. A análise consiste na avaliação dos modelos utilizando-se 1000 reamostragens com substituição, dos pontos de teste. Em cada a réplica é gerado um valor de ROC-ratio, valores maiores que um são obtidos para modelos considerados melhores que a distribuição aleatória. Foi utilizada a taxa de omissão de 5\%. O modelo foi considerado válido quando no mínimo $95 \%$ das réplicas, obtiveram valor maior que 1 (Barve, 2008; Peterson, 2012). Os pontos de teste referem-se aos 30\% dos pontos de cada espécie, separados previamente às análises no Maxent, conforme descrição anterior.

\section{Mapa de Riqueza}

Para mensurar a riqueza dos anfíbios anuros nas diferentes regiões da Caatinga, produziu-se um superfície de riqueza do grupo a partir da sobreposição dos mapas binários. Cabe ressaltar que as mapas binários foram gerados dos modelos binários quando estes foram considerados válidos, dos shapes da IUCN ou dos buffers.

\section{Análise de Endemicidade}

De acordo com DaSilva (2011), área de endemismo (AE) é “uma área onde houve restrição espacial de parte de uma biota causada por um processo comum de isolamento". Área de endemismo são as áreas de convergência da distribuição 
das espécies, sendo uma hipótese da história da diversificação das espécies devido a uma restrição espacial, que pode ser corroborada analisando a filogenia do grupo (DaSilva, 2011).

A metodologia proposta por Szumik et al. (2002), com as alterações implementadas por Szumik \& Goloboff (2004), foi utilizada para identificar as áreas de endemismo na Caatinga. Esta análise foi realizada com o programa NDM/VNDM v.3.0 (Goloboff, 2012). O método identifica áreas de endemismo pela avaliação da concordância da distribuição espacial entre duas ou mais espécies. Para isto a área estudada é divida em quadrículas, sendo estas contrastadas com os dados de ocorrência das espécies.

Para cada espécie é atribuído um índice de endemicidade (IE) que é resultante da avaliação da distribuição total do táxon e a adequação da distribuição à área. Este índice varia de 0 a 1 , sendo o valor máximo obtido quando a espécie apresenta distribuição exatamente igual a área de endemismo encontrada. Assim, quanto maior for a adequabilidade espacial da espécie à área, maior será o índice de endemicidade dessa espécie (Szumik \& Goloboff, 2004). O valor exato do índice de endemicidade para cada espécie, em cada área de endemicidade encontrada foi obtido pelo cálculo da fórmula:

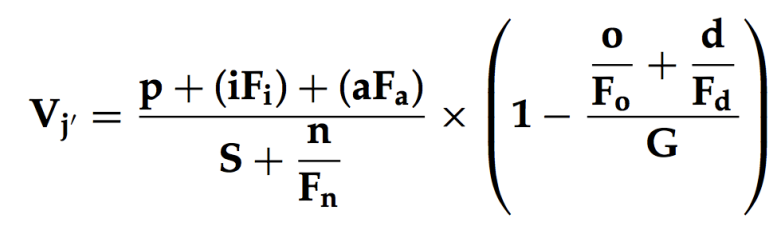

no qual, o índice de endemicidade é representado por $\mathbf{V}_{\mathbf{j}}$, a letra $\mathbf{p}$ é o número de quadrículas da área de endemismo nas quais espécie avaliada ocorre (presença observada - pontos); i, número de quadrículas da área de endemismo nas quais a espécie é inferida (pelo programa); a, número de quadrículas da área de endemismo nas quais a espécie é assumida (modelo); S, número de quadrículas que compõem a área de endemismo; o, número de quadrículas adjacentes à área de endemismo onde a espécie ocorre; d, número de quadrículas adjacentes onde a espécie é assumida; n, número de quadriculas não adjacentes a área de endemismo onde a espécie é assumida, $\mathbf{G}$, numero de quadrículas adjacentes. Há ainda os fatores $\mathbf{F}\left(\mathrm{F}_{\mathrm{i}}, \mathrm{F}_{\mathrm{a}}, \mathrm{F}_{\mathrm{n}}, \mathrm{F}_{\mathrm{o}}\right.$, e $\mathrm{F}_{\mathrm{d}}$ ), aos quais é atribuído um valor, que pode variar de zero a um, dependendo do 
grau de importância referente a cada termo da fórmula (Szumik \& Goloboff, 2004). Embora os valores dos fatores possam ser modificados, utilizou-se os valores padrões do programa $\left(\mathbf{F i}=0,5, \mathbf{F} \mathbf{a}=0,75, \mathbf{F}_{\mathbf{0}}=0,5 ; \mathbf{F} \mathbf{d}=2\right.$ e $\left.\mathbf{F} \mathbf{n}=0,5\right)$.

O valor de endemicidade (VE) de uma área é calculado pela soma dos IE das espécies endêmicas presentes na área. Dessa forma, quanto mais espécies endêmicas estiverem presentes e quanto maior forem seus valores de IE, maior será o suporte da área de endemismo (Szumik \& Goloboff, 2004).

Para esta análise foi construída uma matriz composta por presença observada (1) dos pontos de ocorrência das espécies; presença assumida (2) pelos mapas binários; e ausência (0). Os parâmetros utilizados no programa NDM/VNDM foram: a seleção de áreas com duas ou mais espécies restritas (score $\geq 2.000$ ), mantendo sobrepostos os conjuntos com $50 \%$ de espécies únicas e incluindo as bordas na análise por meio da opção edge proportion, sendo ainda realizadas 100 réplicas para cada matriz analisada.

A escolha dos tamanhos das quadrículas utilizadas nas análises é fundamental e influencia diretamente no resultado obtido (Aagesen et al., 2009; Casagranda et al., 2009; Linder, 2001). Utilizar diferentes tamanhos de quadrículas durante as análises permite o reconhecimento de áreas de endemismo com diferentes características (Casagranda et al., 2009). Desta forma, foram utilizadas seis escalas distintas de quadrículas para estas análises, sendo os tamanhos das quadrículas: $0,5^{\circ} \times 0,5^{\circ}, 1^{\circ} \mathrm{x}$ $1^{\circ}, 2^{\circ} \times 2^{\circ}, 3^{\circ} \times 3^{\circ}, 4^{\circ} \times 4^{\circ}$ e $5^{\circ} \times 5^{\circ}$.

A partir da geração dos resultados intermediários no NDM/VNDM (réplicas das soluções espaciais de endemicidade), foram selecionadas as áreas de consenso entre as soluções. A área consenso tem como objetivo resumir a informação contida nas diferentes áreas de endemismo, quando as mesmas compartilham uma determinada porcentagem de espécies endêmicas (Szumik \& Goloboff, 2004). No caso do programa utilizado, existem dois tipos de consenso; o consenso flexível, no qual uma área individual é incluída à área consenso ao compartilhar uma porcentagem definida de espécies endêmicas com alguma outra área que compõem a área consenso; e o consenso restrito, no qual a área individual deve compartilhar determinada porcentagem de espécies endêmicas com todas as áreas que compõem a área consenso 
(Aagesen et al., 2013; Szumik \& Goloboff, 2004). Neste trabalho utilizou-se o consenso flexível, com $50 \%$ de compartilhamento de espécies endêmicas.

Para as análises de endemicidade foram selecionadas as espécies que apresentaram pelo menos $25 \%$ dos pontos de ocorrência inseridos nos limites da Caatinga. Desta maneira, espécies cuja distribuição é predominante em outros biomas, ou que sua ocorrência possa ser considerada rara na Caatinga, não foram incluídas na análise de áreas de endemismo.

\section{Análise de Agrupamento}

Para avaliar se os padrões de ocorrência espacial dos anfíbios estariam relacionados com as ecorregiões da Caatinga (Velloso et al., 2002), foi feita uma análise de agrupamento. A análise foi realizada com base em matriz de similaridade gerada pela presença/ausência das espécies em unidades de $0,5^{\circ} \times 0,5^{\circ}$ que cobriram toda a área da Caatinga. Os dados usados para presença das espécies em cada quadrícula foram estabelecidos utilizando os pontos de ocorrência das espécies e os mapas de distribuição utilizados (modelos binários e os shapes para as espécies que não puderam ser modeladas), sendo estipulado um limite mínimo de $20 \%$ de ocorrência na quadrícula para que a espécie fosse considerada presente.

Para a análise foram utilizadas 62 das 65 espécies anteriormente citadas, pois as

espécies Bokermannohyla juiju, Corythomantis galeata e Proceratophrys caramaschii não foram consideradas como presentes em nenhuma quadrícula, pois suas distribuições bastante restritas e pouco conhecidas, não ocuparam os $20 \%$ mínimos em nenhuma quadrícula.

A similaridade utilizada para o agrupamento das quadrículas foi calculada pelo índice de Sørensen no pacote recluster (Dapporto et al., 2013) do programa R. Foi utilizado o método agrupamento hierárquico aglomerativo que apresentou a maior correlação entre a matriz de distância e a matriz cofenética, sendo este o método average (Unweighted Pair Group Method With Arithmetic Mean - UPGMA). Após a definição dos grupos foi realizada uma análise de espécies indicadoras (Dufrêne \& Legendre, 1997), utilizando o pacote labdsv (Roberts, 2015) do programa R.

Para verificar se os diferentes grupos encontrados nesta análise concordariam ou não com as ecorregiões propostas por Velloso et al. (2002), realizou-se uma 
análise de correspondência canônica (CCA) usando o pacote vegan (Oksanen et al., 2007) do programa R. Contudo antes desta análise foi realizada ainda, uma seleção progressiva das ecorregiões utilizando o pacote packfor (Dray et al., 2011), para identificar as ecorregiões que apresentam maior contribuição na formação dos grupos. Apenas as ecorregiões selecionadas foram utilizadas na CCA.

\section{Resultados}

As espécies abordadas no estudo geraram uma base de dados de 6.204 pontos únicos de ocorrência. A partir destes dados 38 espécies foram classificadas como de distribuição restrita a região nordeste (Tabela S1) e 18 dessas espécies foram consideradas endêmicas do bioma Caatinga ou da região da Chapada Diamantina, tendo em vista que ao menos $95 \%$ dos pontos de ocorrência dessas espécies estão inseridos nos limites do bioma (Tabela S2).

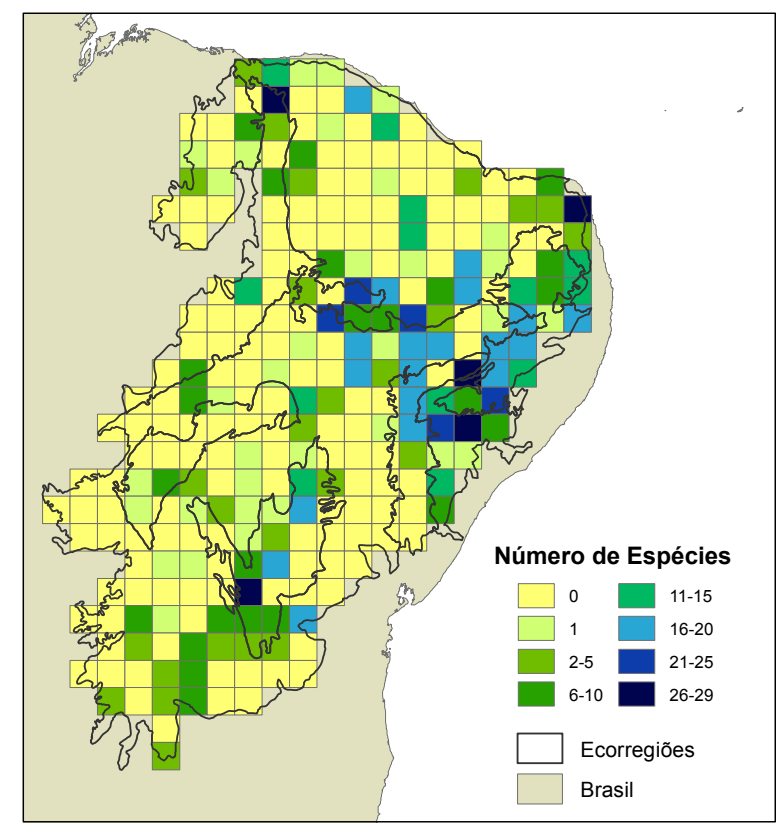

Figura 2. Mapa formado pelo número de espécies distribuídas em quadrículas de $0,5^{\circ} \times 0,5^{\circ}$, baseado nos pontos de ocorrência das espécies.

O mapa de distribuição das espécies em quadrículas de $0,5^{\circ} \times 0,5^{\circ}$ baseado 
apenas em pontos de ocorrência (Figura 2), mostra que 150 quadrículas $(54,5 \%)$ das 275 não apresentaram nenhuma espécie. Poucas quadrículas (5 ou 1,8\% do total) apresentaram entre 26 - 29 espécies. Isso demostra que parte da Caatinga apresenta grandes lacunas de conhecimento sobre sua anurofauna, e que muitas áreas não foram amostradas.

Dez espécies não apresentaram pontos de ocorrência suficientes para a análise de modelagem. Das espécies modeladas, 48 apresentaram modelos estatisticamente significativos pela análise parcial do ROC (Figura S1). As espécies Dendropsophus nanus, Hypsiboas punctatus, Hypsiboas raniceps, Leptodactylus fuscus, Leptodactylus mystaceus, Physalaemus centralis e Physalaemus cuvieri, não apresentam modelos significativos, sendo utilizados então os mapas de distribuição da IUCN como mapas binários.

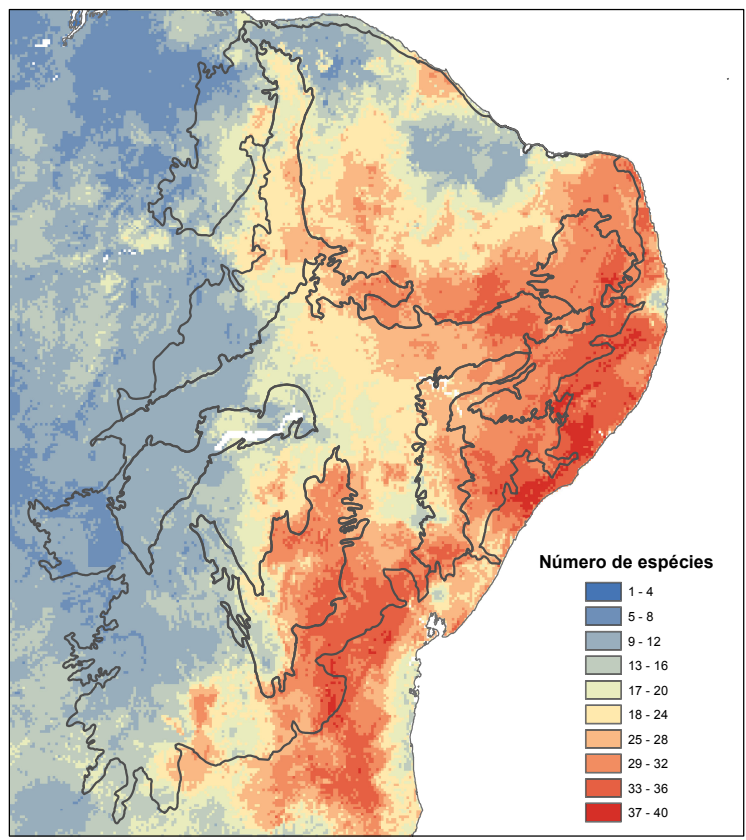

Figura 3. Mapa de riqueza esperada para os anuros na Caatinga baseado na sobreposição dos mapas binários (modelos de distribuição, shapes ou buffers). Em cinza os limites das ecorregiões da Caatinga.

A sobreposição dos pontos e mapas binários de ocorrência gerou um mapa de distribuição potencial da riqueza de anuros para Caatinga (Figura 3). Observa-se então áreas com baixo número de espécies ( $<10$ espécies) e áreas com elevada riqueza, 
podendo chegar a 40 espécies. A região leste do bioma, região adjacente ao bioma Mata Atlântica apresentou elevados valores de riqueza. De mesma forma, as ecorregiões Planalto da Borborema e Raso da Catarina, que são ecorregiões adjacentes a Mata Atlântica, apresentaram ao longo de suas áreas elevadas riquezas. Outras regiões de elevada riqueza observadas no mapa, estão localizadas na ecorregião do complexo da Chapada Diamantina estendendo-se para a Mata Atlântica, e na região que separa as ecorregiões das Depressões Sertanejas.

\section{Análise de endemicidade}

Das espécies abordadas no trabalho, foram selecionadas para esta análise 43 espécies (Tabela S2). Apesar do corte para seleção ter sido estipulado para espécies que apresentassem ao menos $25 \%$ dos pontos de ocorrência inseridos nos limites da Caatinga, todas as espécies selecionadas apresentaram $35 \%$ ou mais da distribuição dos seus pontos no bioma (Tabela S2). As demais espécies apresentaram menos de $22 \%$ dos seus pontos de ocorrência inseridos na Caatinga.

Com exceção da análise de NDM-VNDM pra a escala de $0,5^{\circ}$ x $0,5^{\circ}$, que não apresentou nenhuma área de endemismo, todas as outras escalas utilizadas na análise de endemicidade apontaram ao menos uma área de endemismo. Ao todo foram obtidas 14 áreas consenso (Tabela S3), e uma única área de endemismo para a escala $1^{\circ} \times 1^{\circ}$.

A área de endemismo obtida na análise para quadrículas $1^{\circ} \times 1^{\circ}$ apresentou valor de endemicidade (VE) igual a 3,39 (Figura 4; Figura S2), sendo composta por cinco quadrículas. A área encontrada tem sua extensão exatamente sobreposta à ecorregião do Complexo da Chapada Diamantina e as espécies Bokermannohyla itapoty, Bokermannohyla juiju, Bokermannohyla oxente, Haddadus aramunha, Leptodactylus oreomantis, Proceratophrys minuta e Rupirana cardosoi suportam essa área de endemismo encontrada.

Para a análise de quadrículas $2^{\circ} \times 2^{\circ}$, num total de 15 áreas, foram obtidas cinco áreas consenso com valores de endemicidade de 2,21 - 6,86 (Figura 4; Figura S3). A área consenso 5 (Figura S3 - E), também localizada geograficamente na ecorregião do Complexo da Chapada Diamantina, foi aquela que apresentou o maior 
VE, 6,86 nessa escala. Onze espécies suportam essa área consenso, sendo as mesmas da AE obtida nas quadrículas $1^{\circ} \times 1^{\circ}$, acrescidas de Dendropsophus novaisi, Dendropsophus oliveirai, Leptodactylus caatingae, Pleurodema alium e Pristimantis ramagii.

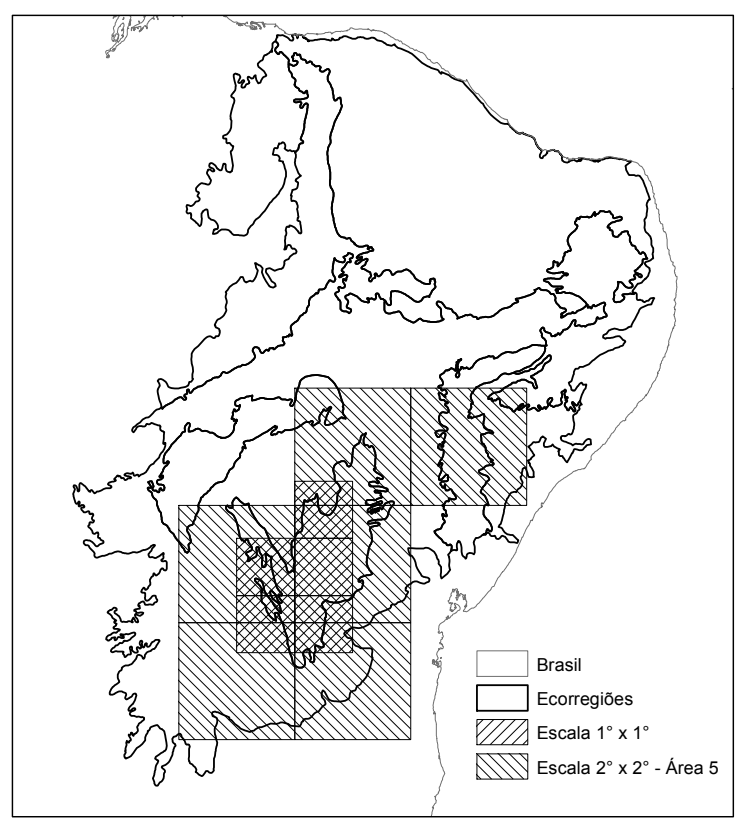

Figura 4. Áreas de endemismo obtidas nas escalas $1^{\circ} \times 1^{\circ}$ e $2^{\circ} \times 2^{\circ}$, que se localizam geograficamente na ecorregião da Chapada Diamantina. A área obtida na escala $2^{\circ} \mathrm{x}$ $2^{\circ}$, trata-se da área consenso 5.

As outras áreas consenso encontradas para a escala $2^{\circ} \times 2^{\circ}$ abrangem todo o bioma. Sendo que a área consenso 3 apresenta o segundo maior valor de endemicidade desta escala, entre 3,36-3,86 (Figura S3 - C). Esta área que abrange a Caatinga e a região norte de Minas é suportada por oito espécies. A área consenso 4 é compostas por Leptodactylus troglodytes, Leptodactylus vastus e Rhinela jimi, espécies típicas da Caatinga, ou seja espécies classificadas como restritas ao bioma e de vasta distribuição no mesmo. A área consenso 1 é sustentada por quatro espécies típicas da Caatinga, e Odontophrynus carvalhoi, que possui afinidade também à Mata Atlântica. A área consenso 2 é representada por Corythomantis greeningi, Leptodactylus troglodytes e Pleurodema diplolister. 
$\mathrm{Na}$ análise feita com quadrículas $3^{\circ} \times 3^{\circ}$, foram obtidas três áreas de endemismo totais, sendo estas resumidas a apenas uma área consenso formada por sete quadrículas (Figura S4). Esta área consenso foi suportada por 24 espécies, apresentando o valor de endemicidade de 13,37. Devido aos elevados índices de endemicidade, nas áreas três áreas totais, oito espécies foram as mais representativas, sendo elas: Bokermannohyla itapoty (IE= 0,714 - 0,764), Bokermannohyla juiju (IE= 0,643 - 0,833), Bokermanohyla oxente ( $\mathrm{IE}=0,643$ - 0,833), Dendropsophus oliveirai $(\mathrm{IE}=0,556$ - 0,786), Haddadus aramunha $(\mathrm{IE}=0,714-0,764)$, Leptodactylus oreomantis $(0,643$ - 0,833), Pleurodema alium $(\mathrm{IE}=0,714$ - 1,000) e Rupirana cardosoi $(\mathrm{IE}=0,643-0,833)$. Como nas escalas mais refinadas, uma das áreas consenso encontradas se mostra relacionada à ecorregião do Complexo da Chapada Diamantina e apresenta o maior VE $(13,82)$. Embora essa região compartilhe 10 espécies com a área consenso 5 da escala $2^{\circ} \times 2^{\circ}$, outras 14 espécies suportam essa área. Desta forma, ainda que as espécies da ecorregião do Complexo da Chapada Diamantina tenham grande relevância para sustentar esta área de endemismo e seu elevado valor de endemicidade, outras espécies de distribuição mais ampla no bioma foram substanciais para obtenção dessa área.

$\mathrm{Na}$ análise com a grade de $4^{\circ} \times 4^{\circ}$ foram encontradas três áreas totais, resumidas em duas áreas consenso (Figura S5). Nesta escala foi obtida uma grande área consenso, abrangendo toda a Caatinga e estendendo-se para o sul. Esta área apresentou um elevado valor de endemicidade $(17,44)$ sendo suportada por 31 espécies. As espécies que apresentaram maiores índices de endemicidade foram Bokermannohyla itapoty $(\mathrm{IE}=0,688-0,800)$, Bokermannohyla oxente $(\mathrm{IE}=0,688-$ 0,800), Dendropsophus novaisi $(\mathrm{IE}=0,688-0,800)$, Haddadus aramunha $(\mathrm{IE}=0,688$ - 0,800), Phyllomedusa bahiana (IE=0,750 - 0,900), e Scinax camposseabrai (IE= 0,688 - 0,800). A área 2 desta escala obteve um valor de endemicidade bastante inferior $(2,22)$, pois apenas três espécies a compõem: Dendropsophus soaresi $(\mathrm{IE}=$ 0,797), Dermatonotus muelleri (IE=0,738) e Physalaemus kroyer $(\mathrm{IE}=0,688)$.

Para maior escala, $5^{\circ} \times 5^{\circ}$, foram encontradas seis áreas consenso, a partir de sete áreas de endemismo. Apenas a área consenso 3 foi formada a partir da união de duas áreas de endemismo, as outras áreas de endemismo não apresentaram similaridade suficiente com outras áreas de endemismo para serem resumidas em uma 
única área consenso, dessa forma as outras cinco áreas consenso representam cinco áreas de endemismo individuais.

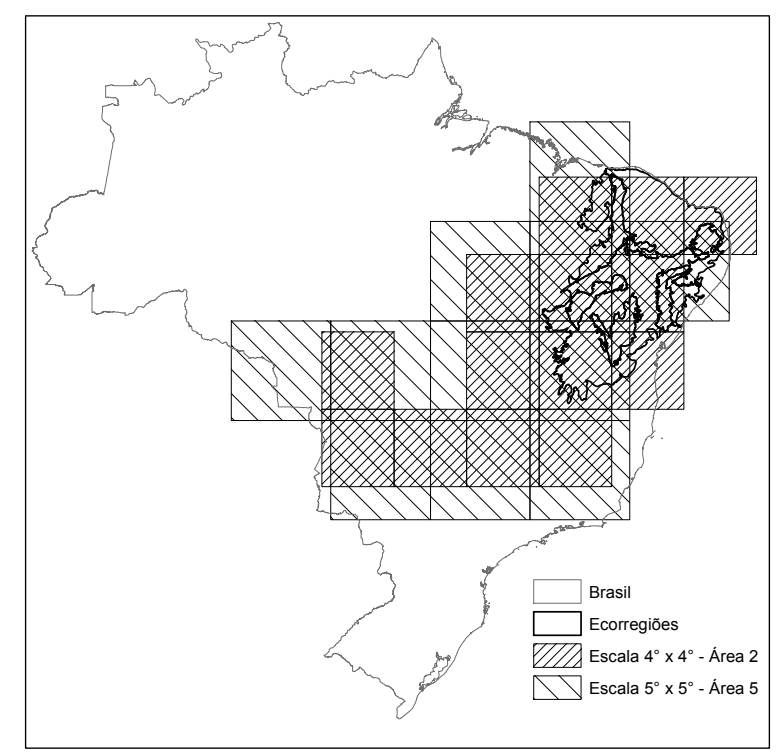

Figura 5. Áreas de endemismo obtidas nas escalas $4^{\circ} \times 4^{\circ}$ e $5^{\circ} \times 5^{\circ}$, que se estendem geograficamente na Caatinga e no Centro-Oeste brasileiro (Cerrado), compondo parte da Diagonal Seca da América do Sul. A área obtida na escala $4^{\circ} \times 4^{\circ}$, trata-se da área consenso 2 e na escala $5^{\circ} \times 5^{\circ}$ a área consenso 5 .

O maior VE foi obtido pela área consenso 4, esta área foi suportada por 26 espécies, apresentando valor de endemicidade de 18,26. Esta área ocupa todo bioma Caatinga se estendendo para parte do bioma Cerrado, tanto na região de Minas Gerais na região norte do Cerrado. A área 1 ocupa a Caatinga e o centro do Brasil, e é suportada por 16 espécies. A área 2 engloba a área central e norte da Caatinga, sendo composta por 10 espécies e a área consenso 3, sustentada por 5 espécies, ocorre na porção sul da Caatinga, avançando para o sudeste brasileiro.

Enquanto que as áreas consenso 1, 2, 3 e 4 apresentaram elevados valores de endemismo e foram suportadas por muitas espécies, as áreas consenso 5 e 6 da escala $5^{\circ} \times 5^{\circ}$, foram suportadas por apenas três espécies. Dendropsophus soaresi (IE = $0,841)$, Dermatonotus muelleri $(\mathrm{IE}=0,682)$ e Physalaemus kroyer $(\mathrm{IE}=0,636)$ foram encontradas na área consenso 5. Esta área esta disposta no nordeste e no centro-oeste brasileiro, ocupando os biomas Caatinga e Cerrado. Dermatonotus muelleri é uma 
espécie de cujo distribuição esta associada as áreas de formações abertas da América do Sul.

A área 6 é formada por 12 quadrículas (23total) que estão dispostas não apenas no território da Caatinga, estende-se para região noroeste, sudeste e parte do entro do Brasil, ocupando parte dos biomas Cerrado e Amazônia. As espécies que formam esta área são: Hypsiboas crepitans $(\mathrm{IE}=0,563)$, Leptodactylus macrosternum $(\mathrm{IE}=0,792)$ e Rhinella granulosa $(\mathrm{IE}=0,719)$

\section{Análise de Agrupamento}

Estipulando-se como ponto de corte a dissimilaridade de $35 \%$, a análise agrupamento baseada na composição de anfíbios nas quadrículas, subdividiu o bioma Caatinga em seis regiões distintas. Tais regiões foram aqui denominadas como Grupo Campo-Maior, Grupo Norte, Grupo Centro-Leste, Grupo Diamantina, Grupo Oeste e Grupo Sul (Figura 6).

Grupo Campo-Maior: assim chamado devido à sua localização na ecorregião do Complexo de Campo Maior. A região que o grupo se localiza apresenta os menores valores de altitude no bioma, 50 a 200 metros.

Grupo Norte: sendo composto por 35 quadrículas, que estão distribuídas principalmente ao norte das ecorregiões Complexo Ibiapaba-Araripe e Depressão Sertaneja Setentrional.

Grupo Centro-Leste: foi o maior grupo encontrado, sendo composto por 153 quadrículas, distribuídas do centro do bioma estendendo-se para o leste até a Mata Atlântica. Essa área ocupa parte das ecorregiões das Depressões Sertanejas Meridional e Setentrional, grande parte da ecorregião do Complexo da Chapada Diamantina, além do Raso da Catarina e Planalto da Borborema.

Grupo Diamantina: o menor grupo obtido, formado apenas por quatro quadrículas, localizadas no sudoeste da ecorregião do Complexo da Chapada Diamantina, onde são encontradas elevadas altitudes, superiores a 1000 metros.

Grupo Oeste: esse grupo está localizado na porção centro-oeste do bioma. A ecorregião Dunas do São Francisco encontra-se inserida nesse grupo, sendo composto 
ainda pela porção sul da ecorregião Complexo Ibiapaba-Araripe e pela porção sudoeste da ecorregião Depressão Sertaneja Meridional.

Grupo Sul: segundo menor grupo encontrado, sendo composto por nove quadrículas localizadas ao sul da Bahia e norte de Minas Gerais.
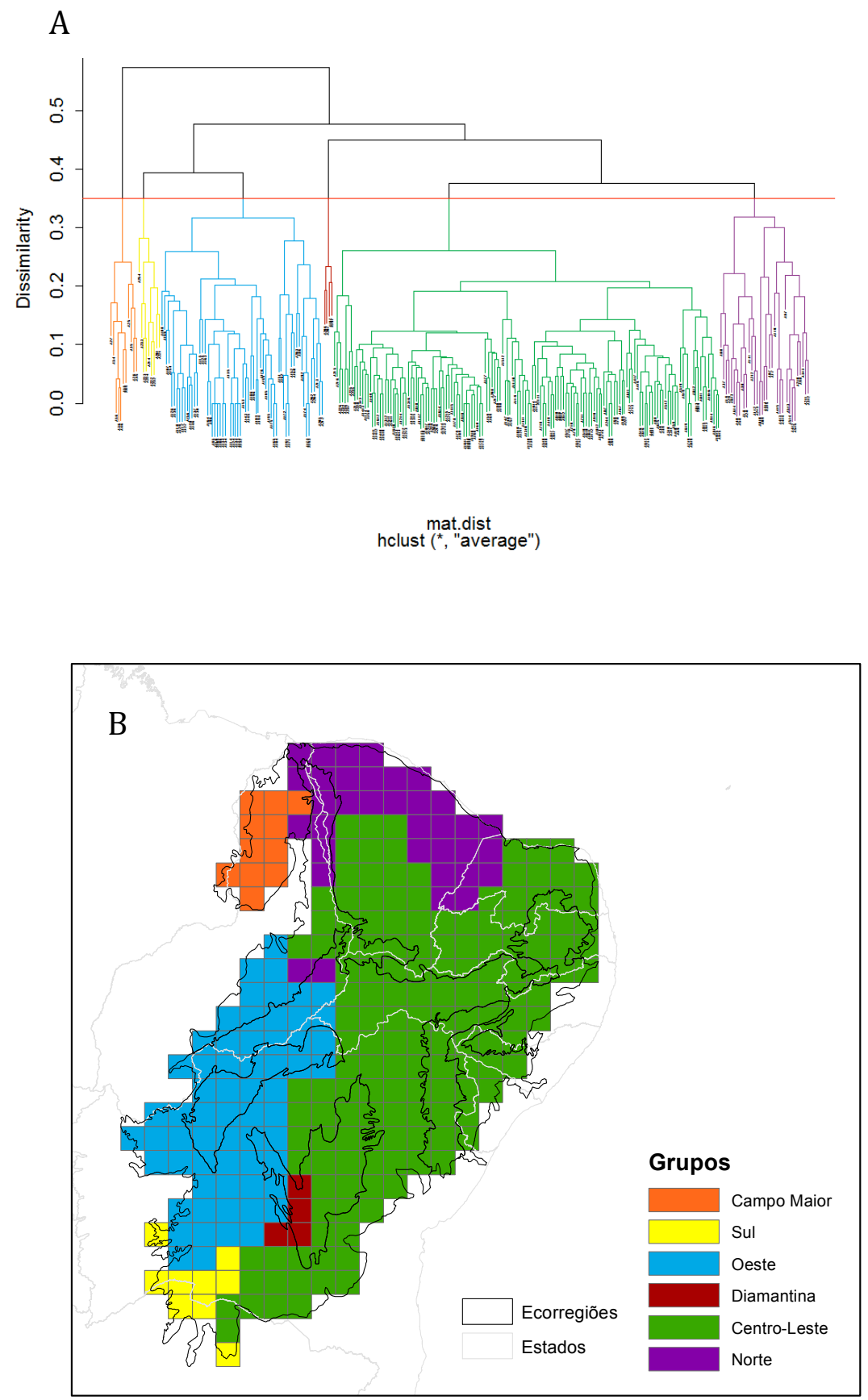

Figura 6. (A) Análise de agrupamento UPGMA, em corte de dissimilaridade de 0,35. 
(B) Os agrupamentos gerados pela análise de agrupamento. Sendo os grupos: em laranja Grupo Campo Maior, em Amarelo Grupo Sul, em azul Grupo Oeste, em vermelho Grupo Diamantina, em verde Grupo Centro-Leste e em roxo o Grupo Norte.

A análise de espécies indicadoras para os grupos formados pela análise de agrupamento, revelou que das 62 espécies avaliadas, 15 espécies foram significativas como espécie indicadora de um dos grupos (Tabela S3). O grupo Campo Maior obteve sete espécies como indicadoras, Dendropsophus rubicundulus, Elachistocheis piauiensis, Leptodactylus andreae, Leptodactylus macrosternum, Leptodactylus pustulatus, Pseudopaludicola pocoto e Scinax fuscomarginatus. As espécies Dendropsophus nanus e Leptodactylus macrosternum foram espécies indicadoras do grupo Sul, Haddadus aramunha foi encontrada para o grupo Oeste, Bokermannohyla itapoty e Hypsiboas albopunctatus para o grupo Diamantina, Physalaemus cicada, Leptodactylus troglodytes e Dermatonotus muelleri as espécies indicadoras do grupo Norte. Nenhuma espécie foi significativa como indicadora do grupo Centro-Leste.

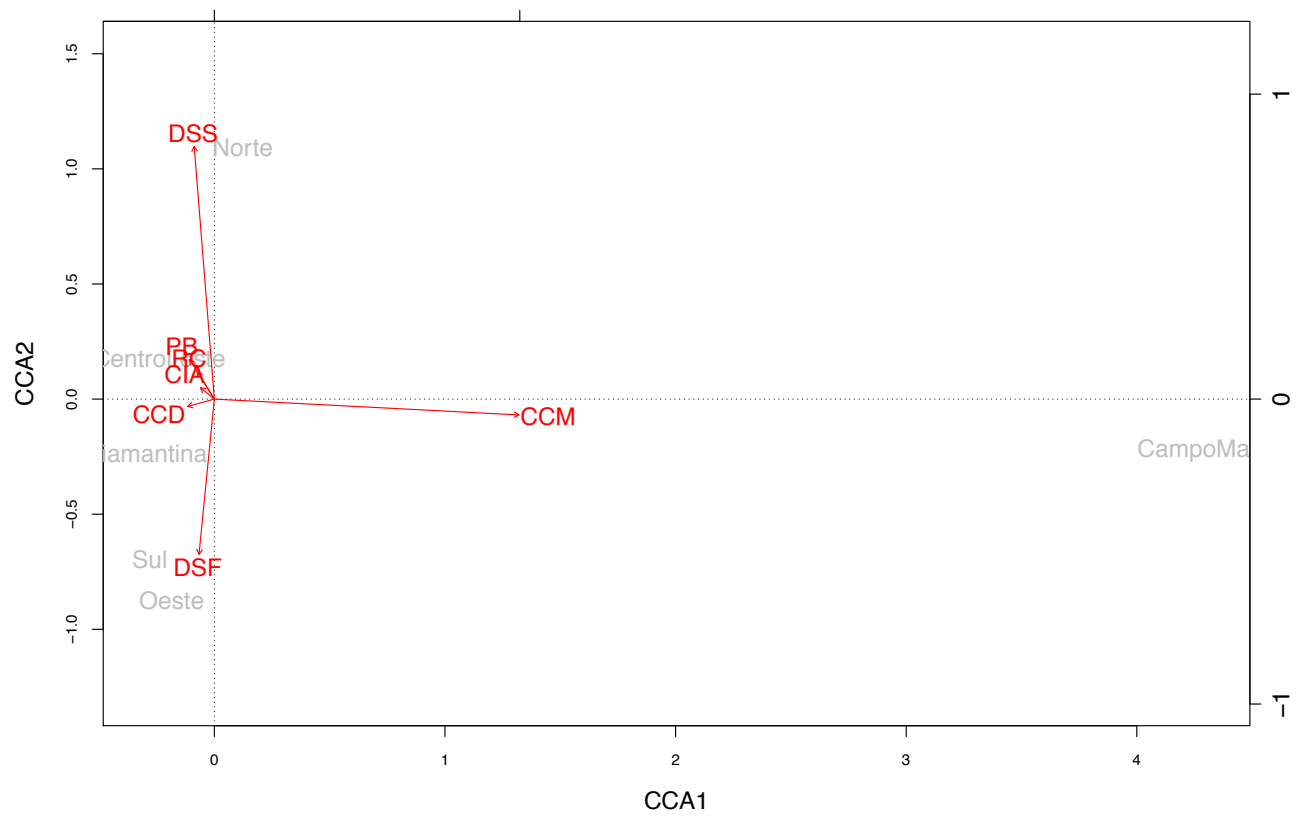

Figura 7. Análise de correlação canônica entre as ecorregiões e os grupos encontrados pela análise de agrupamento. Grupos: Campo Maior (CM), Sul (SU), Oeste (OE), Diamantina (DI), Centro-Leste (CL) e Norte (NO). 
Pela análise de partição da variância, apenas a ecorregião Depressão Sertaneja Meridional não foi selecionada para a análise de correspondência canônica. Posteriormente, o resultado obtido na CCA mostra que o primeiro eixo explica $54,76 \%$ da variância, enquanto o segundo eixo explica $25,50 \%$. Os resultados indicam que o grupo Campo Maior, apresenta correlação com a ecorregião Complexo Campo Maior, sendo esta a maior correlação obtida. O grupo Norte apresentou correlação com a ecorregião Depressão Sertaneja Setentrional. E os grupos Sul e Oeste apresentaram correlação com a ecorregião das Dunas do São Francisco (Figura 7).

\section{Discussão}

O levantamento de dados de anuros na Caatinga mostrou a escassez de informações sobre a distribuição geográfica do grupo no bioma, visto que 54,5\% das quadrículas não apresentaram nenhum ponto de ocorrência, o que corrobora com outros trabalhos que mostram que a Caatinga é um bioma pouco amostrado (Heyer, 1988; Tabarelli \& Silva, 2003; Tabarelli \& Vicente, 2003). Embora ainda pouco estudada, a Caatinga apresentou áreas com expressiva riqueza para o bioma. Os maiores números de espécies foram encontrados na região leste do bioma, na Chapada Diamantina e no ecótono entre as ecorregiões das Depressões Sertanejas. Nas análises de endemicidade realizadas em diferentes escalas, foram obtidas áreas de endemismo localizadas na ecorregião da Chapada Diamantina, áreas referentes a toda extensão da Caatinga e áreas ainda maiores referentes a Diagonal Seca da América do Sul. Pela análise de agrupamento a Caatinga mostra-se ainda como um bioma heterogêneo, dividido em seis grupos distintos.

A riqueza encontrada para Caatinga no presente trabalho é superior à riqueza obtida trabalhos anteriores, onde em áreas melhores amostradas encontraram-se de 21 a 26 espécies de anuros em áreas de Caatinga (Garda et al., 2013; Campos \& Freitas, 2010), ou valores superiores em áreas de ecótono, 35 espécies, área adjacente a Mata Atlântica (Magalhães et al., 2013) e 31 espécies em áreas de ecótono com Cerrado (Ribeiro et al., 2012).

A Mata Atlântica apresenta elevada riqueza de anuros e $88 \%$ das espécies 
presentes são endêmicas deste bioma (Haddad et al., 2013). Este bioma possui condições ambientais extremamente propícias para anfíbios, o fato das regiões da Caatinga adjacentes a Mata Atlântica apresentarem as maiores riquezas encontradas indicam que a o bioma florestal pode influenciar na composição da anurofauna. Outra região de elevada riqueza da Caatinga é a região da Chapada Diamantina, que apresenta-se como um mosaico de fitofisionomias, possuindo ambientes florestais, savânicos e campos, a variedade de ambientes permitem uma ampla diversificação de espécies de anuros, a heterogeneidade de hábitats permite uma maior diversidade de espécies (Buckley \& Jetz, 2007). Em contrapartida, a baixa riqueza encontrada na região oeste do bioma indica que esta região apresenta as condições menos favoráveis do bioma para os anfíbios.

Porém, deve-se ressaltar que os dados de ocorrência das espécies, obtidos para o trabalho, estão concentrados principalmente à nordeste do bioma, na Chapada Diamantina e proximidades. Dessa forma, a elevada riqueza dessas áreas pode ser um viés de amostragem, devido a essas áreas apresentarem levantamentos mais substanciais quando comparados às outras regiões do bioma (Figura 2). Da mesma forma, a baixa diversidade obtida nas regiões no oeste da Caatinga pode ser devida à escassez de dados.

Áreas de endemismo são definidas como áreas de congruência de distribuição de espécies (Szumik et al., 2002), mas os conceitos de endemismo e congruência dependem da escala estudada (Cracraft, 1985). Diferentes trabalhos de Biogeografia da América do Sul e dos Neotrópicos identificaram a região da Caatinga como uma área de endemismo para aves (Cracraft, 1985), primatas (Goldani et al., 2006) ou serpentes (Guedes et al., 2014b). No presente estudo, tendo como corte para análise o limite do território brasileiro, a Caatinga foi igualmente identificada como área de endemismo, sendo encontrada em diferentes escalas analisadas. $\mathrm{Na}$ escalas $2^{\circ} \times 2^{\circ}$ quatro áreas de endemismo obtidas ocupam toda a extensão da Caatinga, estas áreas foram suportadas principalmente por espécies típicas da Caatinga, ou seja, espécies classificadas no trabalho como restritas, mas de distribuição comum no bioma . $\mathrm{Na}$ escala $4^{\circ} \times 4^{\circ}$, a área consenso 1 , também ocupa toda a extensão da Caatinga mas é suportada não apenas pelas espécies típicas do bioma, como por espécies endêmicas da ecorregião da Chapada Diamantina e proximidades. 
Além das áreas de endemismos referentes à extensão da Caatinga, também foram encontradas, nas maiores escalas analisadas, amplas áreas de endemismo, que se estendem por todo nordeste e centro do Brasil (Figura 6), áreas referentes às formações abertas da América do Sul. Os biomas Caatinga, Cerrado e Chaco, que compõem a diagonal de áreas abertas da América do Sul (Vanzollini, 1998) eram consideradas biomas associados. Atualmente, no entanto, diferentes trabalhos agrupam a Caatinga a outros ecossistemas com características bioclimáticas semelhantes, como Florestas Tropicais Sazonalmente Secas (SDTFs, na sigla em inglês) que se encontram estão distribuídas por toda região Neotropical. De todo modo, as SDTFs, o Cerrado e o Chaco, compõem as florestas abertas da América do Sul (Colli, 2005; Werneck, 2011). As áreas de endemismo identificadas neste trabalho corroboram a afinidade biogeográfica entre as vegetações abertas, visto ainda que algumas das espécies que compões essas áreas de endemismo são comuns à esses biomas.

A ecorregião Complexo da Chapada Diamantina foi a única ecorregião na qual encontrou-se uma área de endemismo inserida nos seus limites geográficos, sendo então considerada uma área de endemismo. Nas diferentes escalas abordadas as espécies de distribuição associadas a região da Chapada Diamantina se mostram importantes para identificar não apenas as áreas de endemismo referentes à Chapada (area de endemismo da escala $1^{\circ} \times 1^{\circ}$, área consenso 5 da escala $2^{\circ} \times 2^{\circ}$, Figura 5), mas áreas que ocupam grande parte (área consenso da escala $3^{\circ} \times 3^{\circ}$ ), ou toda a Caatinga (área consenso 1 da escala $4^{\circ} \times 4^{\circ}$ ). Estudos anteriores de biogeografia da herpetofauna identificaram igualmente a Chapada Diamantina como área de endemismo para anuros (Camardelli \& Napoli, 2012), para o gênero Tropidurus (De Carvalho et al., 2013) e para serpentes (Guedes et al. 2014a). As espécies Bokermannohyla juiju, Bokermannohyla itapoty, Rupirana cardosoi e Haddadus aramunha foram encontradas como representantes da área de endemismo da Chapada Diamantina, assim como obtido no trabalho de Camardelli \& Napoli (2012).

A ecorregião do Complexo da Chapada Diamantina apresenta os maiores índices pluviométricos, as menores temperaturas e as maiores altitudes do semiárido nordestino (Velloso et al., 2002), características que fazem esta região ser muito distinta das outras áreas da Caatinga. Estes aspectos permitem que à Chapada Diamantina possua uma fauna única. No entanto, não apenas os fatores 
climáticos atuais, mas também fatores históricos são capazes de explicar o elevado endemismo da região. A Chapada Diamantina compõe a Cadeia do Espinhaço e acredita-se que esta região e a porção mineira do Espinhaço tenham estado conectadas no passado, tendo em vista que algumas espécies filogeneticamente próximas possuem distribuição disjunta, sendo uma espécie na porção baiana (Chapada Diamantina) e outra na porção mineira do Espinhaço. Esta é a situação de espécies como Bokermannohyla itapoty e Bokermannohyla alvarengai, Bokermannohyla oxente e Bokermannohyla saxicola (Leite et al., 2008; Lugli \& Haddad, 2006). A formação de uma barreira geográfica entre as áreas, que posteriormente levou à especiação, é um dos fatores que explicam porque a Chapada Diamantina apresenta um elevado número de espécies endêmicas (Leite et al., 2008).

Para uma análise de áreas de endemismo que pudesse avaliar com segurança a existência de diferenças entre as ecorregiões, seria necessário avaliar a área em quadrantes menores, mas devido à baixa representatividade amostral do território da Caatinga esta avaliação não foi possível. Heyer (1988) identificou a Caatinga como um dos biomas da América do Sul menos conhecidos cientificamente, ao abordar o esforço amostral sobre distribuição de espécies de anfíbios. Embora tenha ocorrido um aumento nos estudos de levantamento na região do semiárido brasileiro, muito ainda se mostra necessário.

A análise de agrupamento a partir da composição da anurofauna resultou na divisão da Caatinga em seis grupos distintos. Estes grupos foram diferentes das ecorregiões de Velloso et al. (2002) e era esperado que realmente houvesse essa baixa associação, uma vez que a delimitação das ecorregiões foi baseada apenas em informações de solo, clima, vegetação, geomorfologia e geologia, não sendo a fauna considerada na elaboração dos limites das ecorregiões. Mesmo assim, há uma forte correlação entre o grupo Campo Maior e a ecorregião Complexo Campo Maior. Esta região da Caatinga parece ser influenciada pelos biomas adjacentes Cerrado e Amazônia, visto que algumas das espécies indicadoras deste grupo estão associadas a essas biomas.

O grupo Oeste mostrou-se correlacionado com a ecorregião das Dunas de São Francisco, áreas localizadas na bacia hidrográfica do rio São Francisco, a oeste da Cadeia do Espinhaço. A formação desse agrupamento pode estar relacionado ao fato 
que a Cadeia do Espinhaço pode ter atuado como uma barreira geográfica para diferentes espécies. O grupo Sul, localizado na Caatinga de Minas Gerais, também apresentou correlação com esta ecorregião.

O grupo Centro Leste localizado na região leste do bioma Caatinga, se mostra associado com diversas ecorregiões, sendo que as ecorregiões Raso da Catarina e Planalto da Borborema, estão inseridas completamente neste grupo. Isto revela que para grupo dos anfíbios, estas ecorregiões não são consideradas distintas. Embora não tenha sido apontada nenhuma espécie como indicadora do grupo, algumas espécies de distribuição restrita foram encontradas apenas em quadrículas desse grupo, o que revela que embora considerada como clado distinto, o grupo Centro Leste, apresenta diferentes composições de anurofauna em sua grande extensão. Pela análise do cladograma nota-se que este grupo apresenta três grandes clados, o que indica que embora estas quadrículas tenham sido agrupadas existem diferenças em suas composições.

As ecorregiões são unidades geográficas estabelecidas com o objetivo de melhorar a eficiência de planejamento da conservação, de forma a maximizar a conservação da variabilidade genética e ecológica (Olson \& Dinnerstein, 1998; Olson et al., 2001), no entanto, a delimitação dessas unidades geográficas é baseada principalmente em aspectos do meio físico da atualidade, mas a distribuição das espécies são também definidas por fatores históricos. Desta forma, embora a definição de ecorregiões seja uma exercício válido, sua aplicação direta em ações de conservação da biota da região é bastante questionável pois, como dito anteriormente, os componentes da fauna não foram considerados nesse exercício de zoneamento. As ações de conservação dos anfíbios da Caatinga requerem análises mais particulares que sejam resultantes de uma integração de processos históricos e ecológicos que influenciaram e influenciam seus representantes.

\section{Conclusões}

Os resultados mostram que os anuros apresentam distribuição heterogênea no bioma, e que a riqueza do grupo pode ser superior ao observado. No entanto, o conhecimento sobre a riqueza e diversidade da Caatinga ainda é escasso, 
existem muitas lacunas de conhecimento no bioma. Em particular a região oeste do bioma é carente em estudos e inventários básicos das espécies do grupo. Ademais, uma vasta revisão taxonômica das espécies da região é também necessária, visto que muitos trabalhos de levantamento apresentam espécies sem identificação precisa, e dessa maneira tornar possível um estudo mais refinado da biogeografia do bioma.

A ausência de dados de distribuição das espécies de anfíbios foi contornada com o uso de modelos de nicho ecológico e os resultados indicam uma certa estruturação espacial das comunidades. A Chapada Diamantina foi identificada como uma região de elevada riqueza e foi identificada como área de endemismo em diferentes escalas abordadas. Assim a Chapada Diamantina se mostra como uma área importante para conservação.

Com base no conhecimento atual da distribuição dos anuros da Caatinga pode-se concluir que embora exista uma correlação entre algumas ecorregiões e os grupos obtidos no trabalho, o padrão de distribuição encontrado para os anfíbios apresenta-se distinto das ecorregiões. Assim para a Ordem Anura, estratégias de conservação devem ser mais particularizadas e não devem ser baseadas nas ecorregiões tendo em vista que as mesmas não representam os padrões de distribuição do grupo. 


\section{Referências Bibliográficas}

Aagesen, L., Szumik, C. A., Zuloaga, F. O., \& Morrone, O. 2009. Quantitative biogeography in the South America highlands - recognizing the Altoandina, Puna and Prepuna through the study of Poaceae. Cladistics, 25(3), 295-310.

Aagesen, L., Szumik, C., \& Goloboff, P. 2013. Consensus in the search for areas of endemism. Journal of Biogeography, 40(11), 2011-2016.

Andrade-Lima, D, 1981. The Caatingas dominium. Revista Brasileira de Botânica 4(2), 149-163.

Bailey, R. G. 1998. Ecoregions. New York: Springer.

Barve, N. 2008. Tool for Partial-ROC. Version 1. Lawrence, K.S.: Biodiversity Institute. Available: http://kuscholarworks.ku.edu/dspace/handle/1808/10059.

Beyer, H.L. 2004. Hawth's Analysis Tools for ArcGIS. Available at http://www.spatialecology.com/htools.

Brown, J.H. \& Lomolino, M.V. 2006. Biogeografia. 2a edição. Funpec. Ribeirão Preto. $692 p$.

Buckley, L. B., \& Jetz, W. 2007. Environmental and historical constraints on global patterns of amphibian richness. Proceedings of the Royal Society of London B: Biological Sciences, 274(1614), 1167-1173.

Camardelli, M., \& Napoli, M. F. 2012. Amphibian conservation in the Caatinga biome and semiarid region of Brazil. Herpetologica, 68(1), 31-47.

Campos, T. F., \& Santos, E. M. 2010. Anurofauna do Parque Nacional do Catimbau (Buíque-PE). In: Moura, GJB, Santos, EM, Oliveira, MAB \& Cabral, MCC (Eds.) Herpetofauna no Estado de Pernambuco. Ministério do Meio Ambiente. Brasília, 219227.

Caramaschi, U. 2006. Redefinição do grupo de Phyllomedusa hypochondrialis, com redescrição de $P$. megacephala (Miranda-Ribeiro, 1926), revalidação de $P$. azurea Cope, 1862 e descrição de uma nova espécie (Amphibia, Anura, Hylidae). Arquivos do Museu Nacional. Rio de Janeiro, 64(2), 159-179.

Carvalho, T. R. de, Leite, F. S. F., \& Pezzuti, T. L. 2013. A new species of 
Leptodactylus Fitzinger (Anura, Leptodactylidae, Leptodactylinae) from montane rock fields of the Chapada Diamantina, northeastern Brazil. Zootaxa, 3701(3), 349364.

Casagranda, D.M., Roig-Juñent, S., \& Szumik, C. 2009. Endemismo a diferentes escalas espaciales: un ejemplo con Carabidae (Coleoptera: Insecta) de América del Sur austral. Revista Chilena de Historia Natural, 82(1), 17-42.

Cassimiro, J., Verdade, V. K., \& Rodrigues, M. T. 2008. A large and enigmatic new eleutherodactyline frog (Anura, Strabomantidae) from Serra do Sincorá, Espinhaço range, northeastern Brazil. Zootaxa, 1761, 59-68.

Colli, G.R., 2005. As origens e a diversificação da herpetofauna do Cerrado. In: Scariot, A., Sousa-Silva, J.C., Felfili, J.M. (Eds.), Cerrado: Ecologia, Biodiversidade e Conservação. Ministério do Meio Ambiente, Distrito Federal, Brasília, 249-264.

Cracraft, J. 1985. Historical biogeography and patterns of differentiation within the South American avifauna: areas of endemism. Ornithological Monographs, 36, 49-84.

Crisci, J.V., Sala, O.E., Katinas, L. \& Posadas, P. 2006. Bridging historical and ecological approaches in biogeography. Australian Systematic Botany, 19(1), 1-10.

Cruz, C. A. G., Nunes I., \& Juncá, F. A. 2012. Redescription of Proceratophrys cristiceps (Müller, 1883) (Amphibia, Anura, Odontophrynidae), with description of two new species without eyelid appendages from northeastern Brazil. South American Journal of Herpetology, 7(2), 110-122.

Dapporto L., Ramazzotti M., Fattorini S., Talavera G., Vila R. \& Dennis R. 2013. Recluster: an unbiased clustering procedure for beta-diversity turnover. Ecography. 36:1070-1075. www.unifi.it/scibio/bioinfo/recluster.html

DaSilva, M. B. 2011. Áreas de endemismo: as espécies vivem em qualquer lugar, onde podem ou onde historicamente evoluíram? Revista da Biologia, 5508, 12-17.

De Carvalho, A. L. G., de Britto, M. R., \& Fernandes, D. S. 2013. Biogeography of the lizard genus Tropidurus Wied-Neuwied, 1825 (Squamata: Tropiduridae): distribution, endemism, and area relationships in South America. PloS One, 8(3), e59736.

De Marco Júnior, P., \& Siqueira, M. F. 2009. Como determinar a distribuição potencial de espécies sob uma abordagem conservacionista. Megadiversidade, 5, 65-76. 
Dray, S., Legendre, P. \& Blanchet, G. 2011. Packfor: Forward Selection with permutation (Canoco p.46). $\mathrm{R}$ package version 0.0-8/r100., (http://r-forge.rproject.org/projects/sedar/).

Dufrêne, M. \& Legendre, P. 1997. Species assemblages and indicator species: the need for a flexible asymmetrical approach. Ecological Monographs, 67(3), 345-366.

Elith, J., Phillips, S. J., Hastie, T., Dudík, M., Chee, Y. E., \& Yates, C. J. 2011. A statistical explanation of MaxEnt for ecologists. Diversity and Distributions, 17(1), 43-57.

Elith, J., \& Graham, C. H. 2009. Do they? How do they? Why do they differ? On finding reasons for differing performances of species distribution models. Ecography, 32(1), 66-77.

ESRI, 2010. ArcGIS 10.0 - Geographical Information System. Environment System Research Institute, Inc., Readlands, California.

Escalante, T., Szumik, C. A \& Morrone, J.J. 2009. Areas of endemism of Mexican mammals: reanalysis applying the optimality criterion. Biological Journal of the Linnean Society, 98(2), 468-478.

Faivovich, J., Lugli, L., Lourenço, A. C. C. \& Haddad, C. F. B. 2009. A new species of the Bokermannohyla martinsi group from central Bahia, Brazil with comments on Bokermannohyla (Anura: Hylidae). Herpetologica 65(3), 303-310.

Fischer, A.G. 1960. Latitudinal variations in organic diversity. Evolution, 14(1), 64-81.

Frost, D. R. 2015. Amphibian Species of the World: an Online Reference. Version 6.0 (Date of access). Electronic Database accessible at http://research.amnh.org/herpetology/amphibia/index.html. American Museum of Natural History, New York, USA.

Garda, A.A., Costa, T.B., Santos-Silva, C.R., Mesquita, D.O., Faria, R.G., Conceição, B.M., Silva, I.R.S, Ferreira, A.S., Rocha, S.M., Palmeira, C.N.S., Rodrigues, R., Ferrari, S.F., \& Torquato, S. 2013. Herpetofauna of protected areas in the Caatinga I: Raso da Catarina Ecological Station (Bahia, Brazil). Check List, 9(2), 405-414.

Gaston, K. J. 2000. Global patterns in biodiversity. Nature 405(6783), 220-227.

Giannini, T.C., Siqueira, M.F., Acosta, A.L.; Barreto, F.C.C, Saraiva, A.M. \& Alves- 
dos-Santos, I. 2012. Desafios atuais da modelagem preditiva de distribuição de espécies. Rodriguésia-Instituto de Pesquisas Jardim Botânico do Rio de Janeiro, 63(3), 733-749.

Giulietti, A. M., Bocage Neta, A. L., Castro, A. A. J. F., Gamarra-Rojas, C. F. L., Sampaio, E. V. S. B., Virgínio, J. F., Queiroz, L. P., Figueiredo, M. A., Rodal, M. J, N, Barbosa, M. R. V. \& Harley, R. M. 2004. Diagnóstico da vegetação nativa do bioma Caatinga. Pg. 48-90 in J. M. C. Silva, M. Tabarelli, M. Fonseca, \& L. Lins, editors. Biodiversidade da Caatinga: áreas e ações prioritárias para a conservação. Ministério do Meio Ambiente, Brasília.

Goldani, A., Carvalho, G. S., \& Bicca-Marques, J. C. 2006. Distribution patterns of Neotropical primates (Platyrrhini) based on parsimony analysis of endemicity. Brazilian Journal of Biology, 66(1A), 61-74.

Goloboff, P.A. 2012. NDMWNDM. Programs for identification of areas of endemism. Program and documentation. Available at: http://www.zmuc.dk/public/phylogeny/endemism/.

Guedes, T. B., Sawaya, R. J., \& C Nogueira, C. 2014a. Biogeography, vicariance and conservation of snakes of the neglected and endangered Caatinga region, north-eastern Brazil. Journal of Biogeography, 41(5), 919-931.

Guedes, T. B., Nogueira, C., \& Marques, O. A. 2014b. Diversity, natural history, and geographic distribution of snakes in the Caatinga, Northeastern Brazil. Zootaxa, 3863(1), 1-93.

Guisan, A., \& Zimmermann, N. E. 2000. Predictive habitat distribution models in ecology. Ecological Modelling, 135(2), 147-186.

Haddad, C. F. B., Toledo, L. F., Prado, C. P. A., Loebmann, D., Gasparini, J. L., \& Sazima, I. 2013. Guia dos Anfíbios da Mata Atlântica: diversidade e biologia. Anolisbook, São Paulo, 544p.

Heyer, W. R. 1988. On frog distribution patterns east of the Andes. In: Heyer, W. R. \& Vanzolini, P. E. (Eds.) Proceedings of a workshop on neotropical distribution patterns. Academia Brasileira de Ciências, Rio de Janeiro, Brasil. 245-273

Hijmans, R. J., Cameron, S. E., Parra, J. L., Jones, P. G., \& Jarvis, A. 2005. Very high resolution interpolated climate surfaces for global land areas. International 
Journal of Climatology, 25(15),1965-1978.

Hoffmann, M., Hilton-Taylor, C., Angulo, A., Böhm, M., Brooks, T. M., Butchart, S. H., ... \& Collett, L. C. 2010. The impact of conservation on the status of the world's vertebrates. science, 330(6010), 1503-1509.

IBGE (Instituto Brasileiro de Geografia e Estatística). 2004. Biomas do Brasil (1:5.000.000). IBGE-Departamento de Cartografia (DECAR), Rio de Janeiro, Brazil. Available at: http://mapas.mma.gov.br/i3geo/datadownload.htm

IUCN. 2014. Red List Spatial Data - Amphibians. Data do acesso: 10/out/2014. Disponível em http://www.iucnredlist.org/technical-documents/spatial-data.

Leal, I. R., da Silva, J., Cardoso, M., Tabarelli, M., \& Lacher, T. E. 2005. Changing the course of biodiversity conservation in the Caatinga of northeastern Brazil. Conservation Biology, 19(3), 701-706.

Legendre, P. \& Fortin, M. J. 1989. Spatial pattern and ecological analysis. Vegetatio, 80(2), 107-138.

Leite, F.S.F.; Juncá, F. A \& Eterovick, P.C. 2008 Status do conhecimento, endemismo e conservação de anfíbios anuros da Cadeia do Espinhaço, Brasil. Megadiversidade 4(12), 182-200.

Linder, H. P., 2001. Plant diversity and endemism in sub-Saharan tropical Africa. Journal of Biogeography, 28(2), 169-182.

Liu, C., White, M., \& Newell, G. 2013. Selecting thresholds for the prediction of species occurrence with presence-only data. Journal of Biogeography, 40(4), 778-789.

Lomolino, M.V. 2004. Conservation biogeography. In: Lomolino, M.V. \& Heaney, L.R. (Eds) Frontiers of Biogeography: new directions in the geography of nature. pp. 293296. Sinauer Associates, Sunderland, Massachusetts.

Lugli, L. \& Haddad, C.F. 2006a. A new species of the Bokermannohyla pseudopseudis group from central Bahia, Brazil (amphibia, hylidae). Journal of Herpetology, 40(1), 7-15.

Lugli, L., \& Haddad, C.F.B. 2006b. A new species of the Bokermannohyla pseudopseudis group from central Bahia, Brazil (Amphibia, Hylidae). Herpetologica, 62(4), 453-465. 
Maciel, D. B., \& Nunes, I. 2010. A new species of four-eyed frog genus Pleurodema Tschudi, 1838 (Anura: Leiuperidae) from the rock meadows of Espinhaço range, Brazil. Zootaxa, 2640, 53-61.

Magalhães, F. D. M., Dantas, A. K. B. P., Brito, M. R. M., Medeiros, P. H. S., Oliveira, A. F., Pereira, T. C. S. O., Queiroz, M. H. C., Santana, D.J, Silva, W. P. \& Garda, A. A. 2013. Anurans from an Atlantic Forest-Caatinga ecotone in Rio Grande do Norte State, Brazil. Herpetology Notes, 6, 1-10.

Magalhães, F. M., Loebmann, D., Kokubum, M. N. C., Haddad, C. F. B. \& Garda, A. A. 2014. A new species of Pseudopaludicola (Anura: Leptodactylidae: Leiuperinae) from northeastern Brazil. Herpetologica, 70(1), 77-88.

MMA (Ministério do Meio Ambiente). 2002. Biodiversidade brasileira: avaliação e identificação de áreas e ações prioritárias para conservação, utilização sustentável e repartição de benefícios da biodiversidade brasileira. Secretaria de Biodiversidade e Florestas. MMA, Brasília.

MMA (Ministério do Meio Ambiente). 2004. Biodiversidade da Caatinga: áreas e ações prioritárias para conservação. Secretaria de Biodiversidade e Florestas. MMA, Brasília.

MMA (Ministério do Meio Ambiente). 2007. Áreas prioritárias para conservação, uso sustentável e repartição de benefícios da biodiversidade brasileira. Atualização Portaria MMA No. 9, de 23 de janeiro de 207. Secretaria de Biodiversidades e Florestas. MMA, Brasília.

Napoli, M. F. \& Juncá, F. A. 2006. A new species of the Bokermannohyla circumdata group (Amphibia: Anura: Hylidae) from Chapada Diamantina, State of Bahia, Brazil. Zootaxa, 1244, 57-68.

Napoli, M. F., Cruz, C. A. G., de Abreu, R. O. \& Del Grande, M. L. 2011. A new species of Proceratophrys Miranda-Ribeiro (Amphibia: Anura: Cycloramphidae) from the Chapada Diamantina, State of Bahia, northeastern Brazil. Zootaxa, 3133, 37-49.

Oksanen, J., Kindt, R., Legendre, P., O’Hara, B., Stevens, M. H. H., Oksanen, M. J., \& Suggests, M. A. S. S. 2007. The vegan package. Community ecology package.

Olson, D.M., \& Dinerstein, E., 1998. The Global 200: a representation approach to conserving the Earth's most biologically valuable ecoregions. Conservation 
Biology 12(3), 502-515.

Olson, D. M., Dinerstein, E., Wikramanayake, E. D., Burgess, N. D., Powell, G. V., Underwood, E. C., D’Amico, J.A., Itoua, I., Strand, H.E., Morrison, J.C., Loucks, C.J., Allnutt, T.F., Ricketts, T.H., Kura, Y., Lamoreux, J.F., Wettengel \& Kassem, K. R. 2001. Terrestrial Ecoregions of the World: A New Map of Life on Earth A new global map of terrestrial ecoregions provides an innovative tool for conserving biodiversity. BioScience, 51(11), 933-938.

Ortega-Huerta, M. A., \& Peterson, A. T. 2004. Modelling spatial patterns of biodiversity for conservation prioritization in north-eastern Mexico. Diversity and Distributions 10(1),39-54.

Peterson, A.T., 2001. Predicting species' geographic distributions based on ecological niche modeling. The Condor, 103(3), 599-605.

Peterson, A.T. 2012. Niche modeling: model evaluation. Biodiversity Informatics, 8(1).

Peterson, A.T., Ortega-Huerta, M.A., Bartley, J., Sánchez-Cordero, V., Soberón, J., Buddemeier, R.H., \& Stockwell, D.R. 2002. Future projections for Mexican faunas under global climate change scenarios. Nature, 416 (6881), 626-629.

Peterson, A.T., Papeş, M. \& Soberón, J. 2008. Rethinking receiver operating characteristic analysis applications in ecological niche modeling. Ecological Modelling, 213(1), 63-72.

Phillips, S.J., Anderson, R.P., \& Schapire, R.E. 2006. Maximum entropy modeling of species geographic distributions. Ecological Modelling, 190(3),231-259.

Platnick, N. I. 1991. On areas of endemism. Australian Systematic Botany, 4(1), 11-12.

Polasky, S. \& Solo, A.R. 2001. The value of information in reserve site selection. Biodiversity and Conservation, 10(7), 1051-1058.

Pombal, J. P. Jr., Menezes, V. A., Fontes, A. F., Nunes, I., da Rocha, C. F. D. \& Van Sluys, M. 2012. A second species of the casque-headed frog genus Corythomantis (Anura: Hylidae) from northeastern Brazil, the distribution of C. greeningi, and comments on the genus. Boletim do Museu Nacional. Nova Serie, Zoologia. Rio de Janeiro, 530, 1-14.

Posadas, P., Crisci, J. V., \& Katinas, L. 2006. Historical biogeography: a review of its 
basic concepts and critical issues. Journal of Arid Environments, 66(3), 389-403.

Prado, D. 2003. As caatingas da América do Sul. In: Leal, I.R., Tabarelli, M. \& Silva, J.M.C. (eds.). Ecologia e conservação da Caatinga. pp. 3-73. Editora Universitária, Universidade Federal de Pernambuco, Recife, Brasil.

R Development Core Team 2014. R: A language and environment for statistical computing. R Foundation for Statistical Computing, Vienna, Austria. Available at: http://www.R-project.org/

Ribeiro, S. C., Roberto, I.J., Sales, D.L., Ávila, R. W., \& Almeida, W.D.O. 2012. Amphibians and reptiles from the Araripe bioregion, northeastern Brazil. Salamandra, 48(3), 133-146.

Roberts, D. W. 2015. Labdsv: Ordination and Multivariate Analysis for Ecology. R version 1.7-0.

Rodrigues, M.T. 1996. Lizards, snakes, and amphisbaenians from the quaternary sand dunes of the middle Rio São Francisco, Bahia, Brazil. Journal of Herpetology, 30(4), 513-523.

Rodrigues, M.T. 2003. Herpetofauna da Caatinga. In: Leal, I.R., Tabarelli, M., \& Silva, J.M.C. (eds). pp. 181-236. Ecologia e conservação da Caatinga. Editora Universitária, Universidade Federal de Pernambuco, Recife, Brasil.

SBH (Sociedade Brasileira de Herpetologia). 2012. Brazilian amphibians - List of species. Accessible at http://www.sbherpetologia.org.br.

SBH (Sociedade Brasileira de Herpetologia). 2014. Brazilian amphibians - List of species. Accessible at http://www.sbherpetologia.org.br.

Sclater, P.L. 1858. On the general geographical distribution of the members of the class Aves. Journal of the Proceedings of the Linnean Society of London. Zoology, 2(7), $130-136$.

Silva, J.M.C., Tabarelli M., Fonseca M.T. \& Lins, L.V. (Orgs.). 2004. Biodiversidade da Caatinga: áreas e ações prioritárias para a conservação. Ministério do Meio Ambiente, Brasília.

Silvano, D. L., \& Segalla, M. V. 2005. Conservação de anfíbios no Brasil. Megadiversidade, 1(1), 79-86. 
Siqueira, M.D., \& Peterson, A. T. 2003. Consequences of global climate change for geographic distributions of cerrado tree species. Biota Neotropica, 3(2), 1-14.

Szumik, C., Cuezzo, F., Goloboff, P., \& Chalup, A. 2002. An optimality criterion to determine areas of endemism. Systematic Biology, 51(5), 806-816.

Szumik, C. \& Goloboff, P. 2004. Areas of endemism: an improved optimality criterion. Systematic Biology, 53(6), 968-977.

Tabarelli, M. \& Silva, J.M.C. 2003. Áreas e ações prioritárias para a conservação da biodiversidade da Caatinga. In: Leal, I.R., Tabarelli, M., \& Silva, J.M.C. (Eds.). Ecologia e conservação da Caatinga. pp. 777 - 796. Editora Universitária, Universidade Federal de Pernambuco, Recife, Brasil.

Tabarelli, M. \& Vicente., A. 2003. Conhecimento sobre plantas lenhosas da Caatinga: lacunas geográficas e ecológicas. In: Leal, I.R., Tabarelli, M., Fonseca, M.T. \& Lins, L.V. (Orgs.). Biodiversidade da Caatinga: áreas e ações prioritárias para a conservação. pp. 101-111. Ministério do Meio Ambiente, Brasília.

Vanzolini, P. E. 1963. Problemas faunísticos do cerrado: 60-85. In: Ferri, M. G. (Ed.), Simpósio sobre o Cerrado, 1-310. São Paulo.

Vanzolini, P.E. 1974. Ecological and geographical distribution of lizards in Pernambuco, northeastern Brasil (Sauria). Papéis Avulsos Zoologia, São Paulo, 28, 61-90.

Vanzolini, P.E. 1976. On the lizards of a Cerrado-Caatinga contact: evolutionary and zoogeographical implications (Sauria). Papéis Avulsos de Zoologia, São Paulo, 29, 111-119.

Velloso, A.L., Sampaio, E.V.S.B., \& Pareyn F.G.C. 2002. Ecorregiões-Proposta Para o Bioma Caatinga. Associação Plantas do Nordeste/Instituto de Conservação Ambiental, The Nature Conservancy do Brasil, Brazil.

Werneck, F. P. 2011. The diversification of eastern South American open vegetation biomes: historical biogeography and perspectives. Quaternary Science Reviews, 30(13), 1630-1648.

Whittaker, R. J., Araújo, M. B, Jepson, P. Ladle, R. J., Watson, J. E. M., \& Willis, K. J. 2005. Conservation Biogeography: assessment and prospect. Diversity and Distributions, 11(1), 3-23. 
Wiens, J. J., \& Donoghue, M. J. 2004. Historical biogeography, ecology and species richness. Trends in Ecology \& Evolution, 19(12), 639-644.

Wisz, M. S., Hijmans, R. J., Li, J., Peterson, A. T., Graham, C. H., \& Guisan, A. 2008. Effects of sample size on the performance of species distribution models. Diversity and Distributions, 14(5), 763-773.

Young, B. E., Lips, K. R., Reaser, J. K., Ibáñez, R., Salas, A. W., Cedeño, J. R., Coloma, L.A., Ron, S., La Marca, E., Meyer, J. R., Muñoz, A., Bolaños, F. Chaves, G. \& Romo, D. 2001. Population declines and priorities for amphibian conservation in Latin America. Conservation Biology, 15(5), 1213-1223. 


\section{Material Suplementar}

Tabela S1. Lista das espécies utilizadas no trabalho. Mostrando sua definição como ampla ou restrita de acordo com sua distribuição e os números de pontos usados para treino e teste.

\begin{tabular}{|c|c|c|c|c|}
\hline Espécie & Distribuição & $\begin{array}{c}\text { Pontos } \\
\text { Totais } \\
\end{array}$ & $\begin{array}{l}\text { Pontos } \\
\text { Treino } \\
\end{array}$ & $\begin{array}{c}\text { Pontos } \\
\text { Teste } \\
\end{array}$ \\
\hline \multicolumn{5}{|l|}{ Família Bufonidae } \\
\hline Rhinella granulosa & Ampla & 218 & 153 & 65 \\
\hline Rhinella jimi & Restrita & 126 & 88 & 38 \\
\hline Rhinella rubescens & Ampla & 51 & 36 & 15 \\
\hline Família Ceratophryidae & & 0 & & \\
\hline Ceratophrys joazeirensis & Restrita & 12 & 8 & 4 \\
\hline Haddadus aramunha & Restrita & 13 & 9 & 4 \\
\hline Pristimantis ramagii & Restrita & 31 & 22 & 9 \\
\hline \multicolumn{5}{|l|}{ Família Hylidae } \\
\hline Bokermannohyla diamantina & Restrita & 7 & - & - \\
\hline Bokermannohyla itapoty & Restrita & 13 & 9 & 4 \\
\hline Bokermannohyla juiju & Restrita & 2 & - & - \\
\hline Bokermannohyla oxente & Restrita & 23 & 16 & 7 \\
\hline Corythomantis galeata & Restrita & 1 & - & - \\
\hline Corythomantis greeningi & Restrita & 91 & 64 & 27 \\
\hline Dendropsophus branneri & Restrita & 61 & 43 & 18 \\
\hline Dendropsophus decipiens & Ampla & 79 & 55 & 24 \\
\hline Dendropsophus elegans & Ampla & 152 & 106 & 46 \\
\hline Dendropsophus minutus & Ampla & 543 & 380 & 163 \\
\hline Dendropsophus nanus & Ampla & 243 & 170 & 73 \\
\hline Dendropsophus novaisi & Restrita & 7 & - & - \\
\hline Dendropsophus oliveirai & Restrita & 28 & 20 & 8 \\
\hline Dendropsophus rubicundulus & Ampla & 73 & 51 & 22 \\
\hline Dendropsophus soaresi & Restrita & 50 & 35 & 15 \\
\hline Hypsiboas albopunctatus & Ampla & 51 & 36 & 15 \\
\hline Hypsiboas crepitans & Ampla & 81 & 57 & 24 \\
\hline Hypsiboas punctatus & Ampla & 82 & 57 & 25 \\
\hline Hypsiboas raniceps & Ampla & 329 & 230 & 99 \\
\hline Phyllodytes acuminatus & Restrita & 8 & - & - \\
\hline Phyllomedusa bahiana & Restrita & 34 & 24 & 10 \\
\hline Phyllomedusa nordestina & Restrita & 99 & 69 & 30 \\
\hline Scinax camposseabrai & Restrita & 8 & - & - \\
\hline Scinax fuscomarginatus & Ampla & 192 & 134 & 58 \\
\hline Scinax fuscovarius & Ampla & 484 & 339 & 145 \\
\hline Scinax nebulosus & Ampla & 73 & 51 & 22 \\
\hline Scinax pachycrus & Restrita & 50 & 35 & 15 \\
\hline
\end{tabular}


Tabela S1 (Cont.). Lista das espécies utilizadas no trabalho. Mostrando sua definição como ampla ou restrita de acordo com sua distribuição e os números de pontos usados para treino e teste.

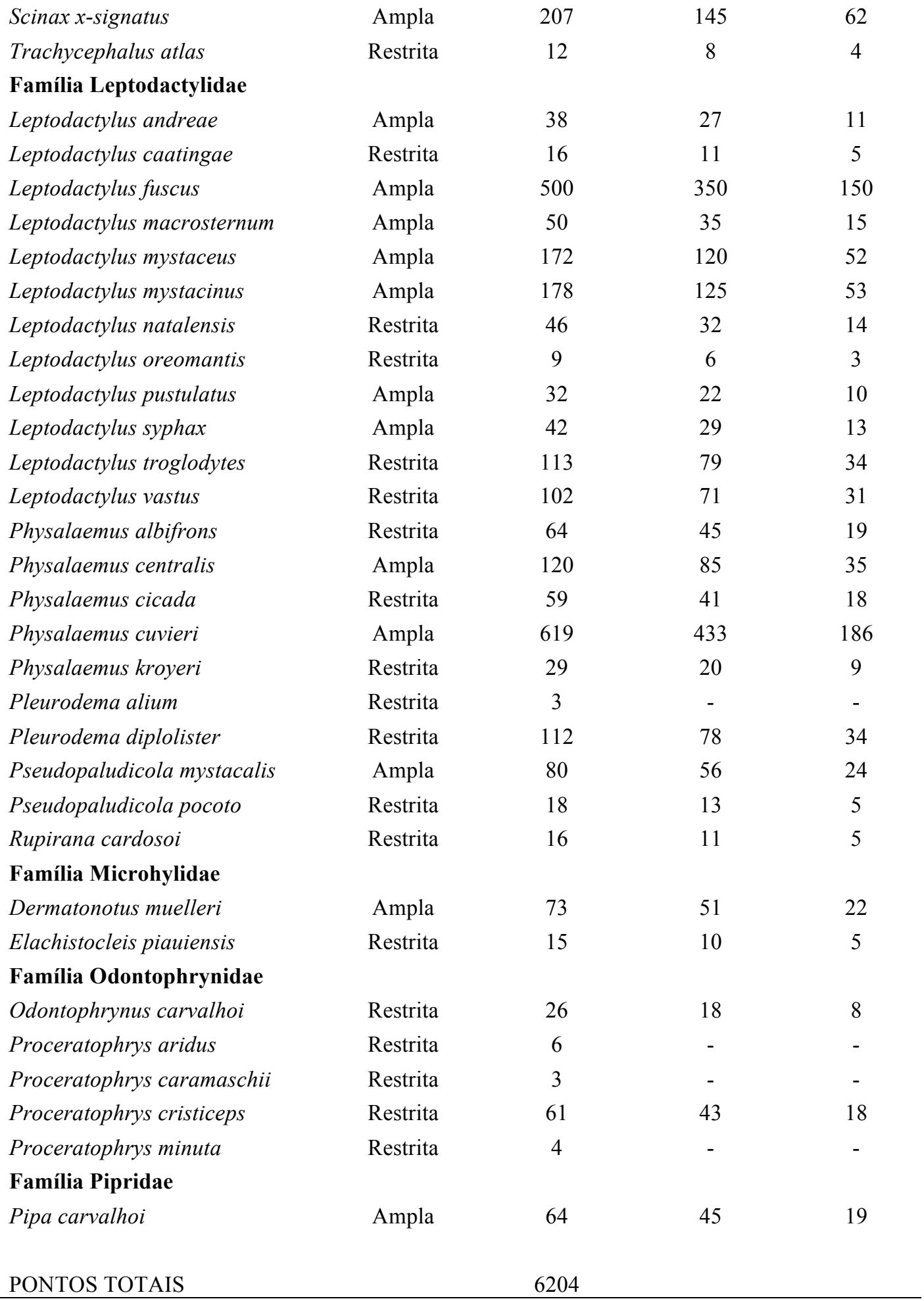


Figura S1. Mapas binários de distribuição das espécies.
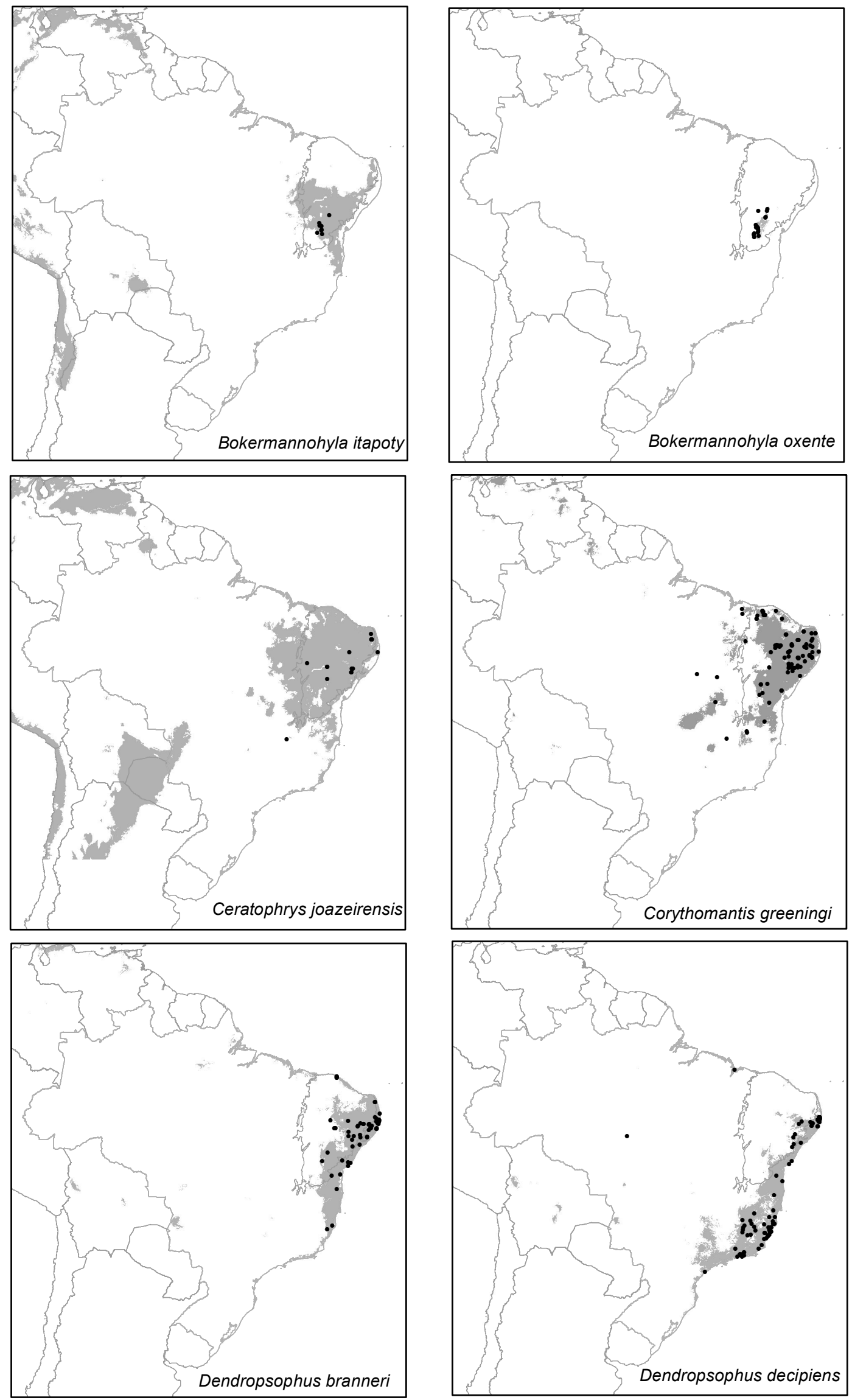

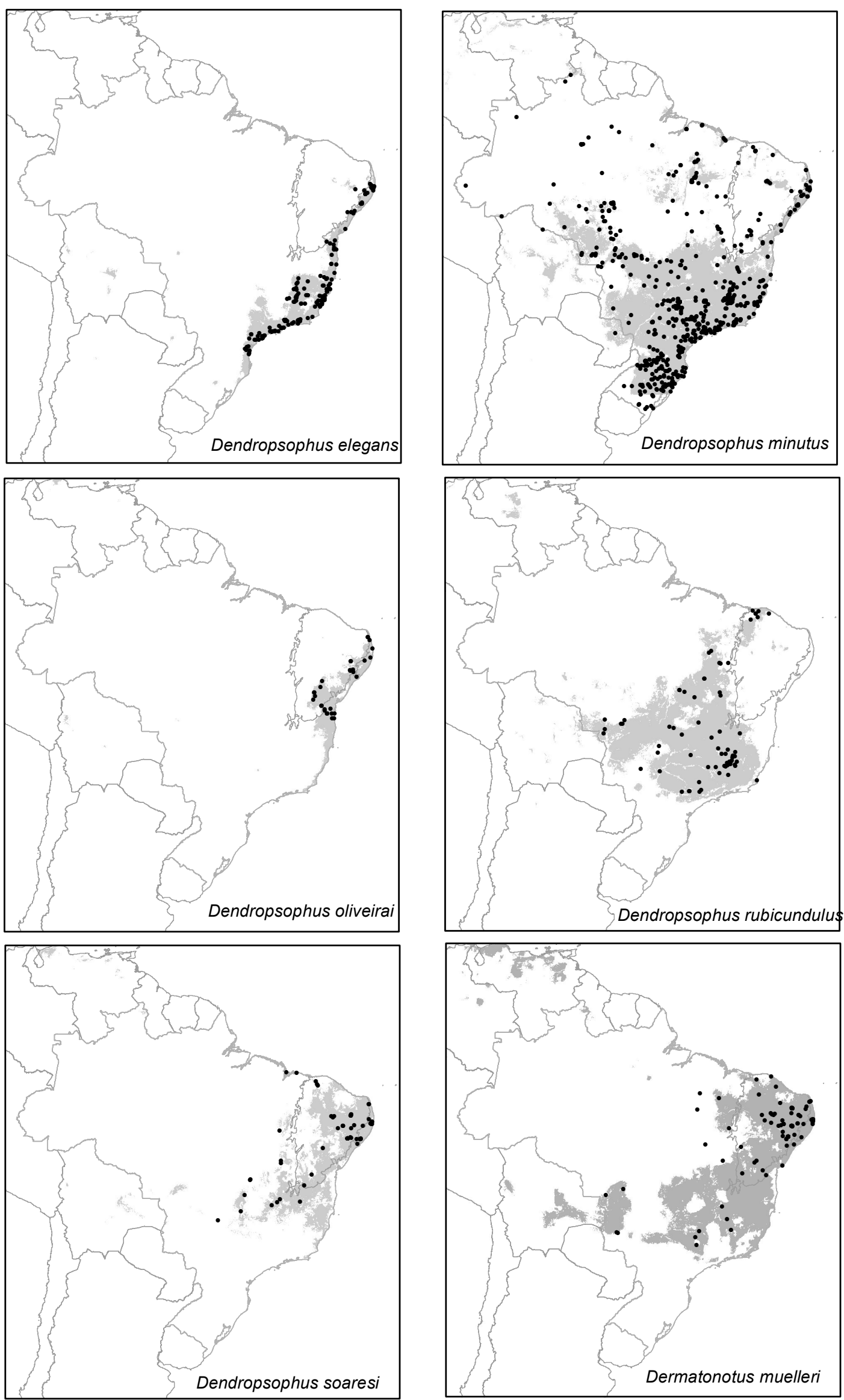

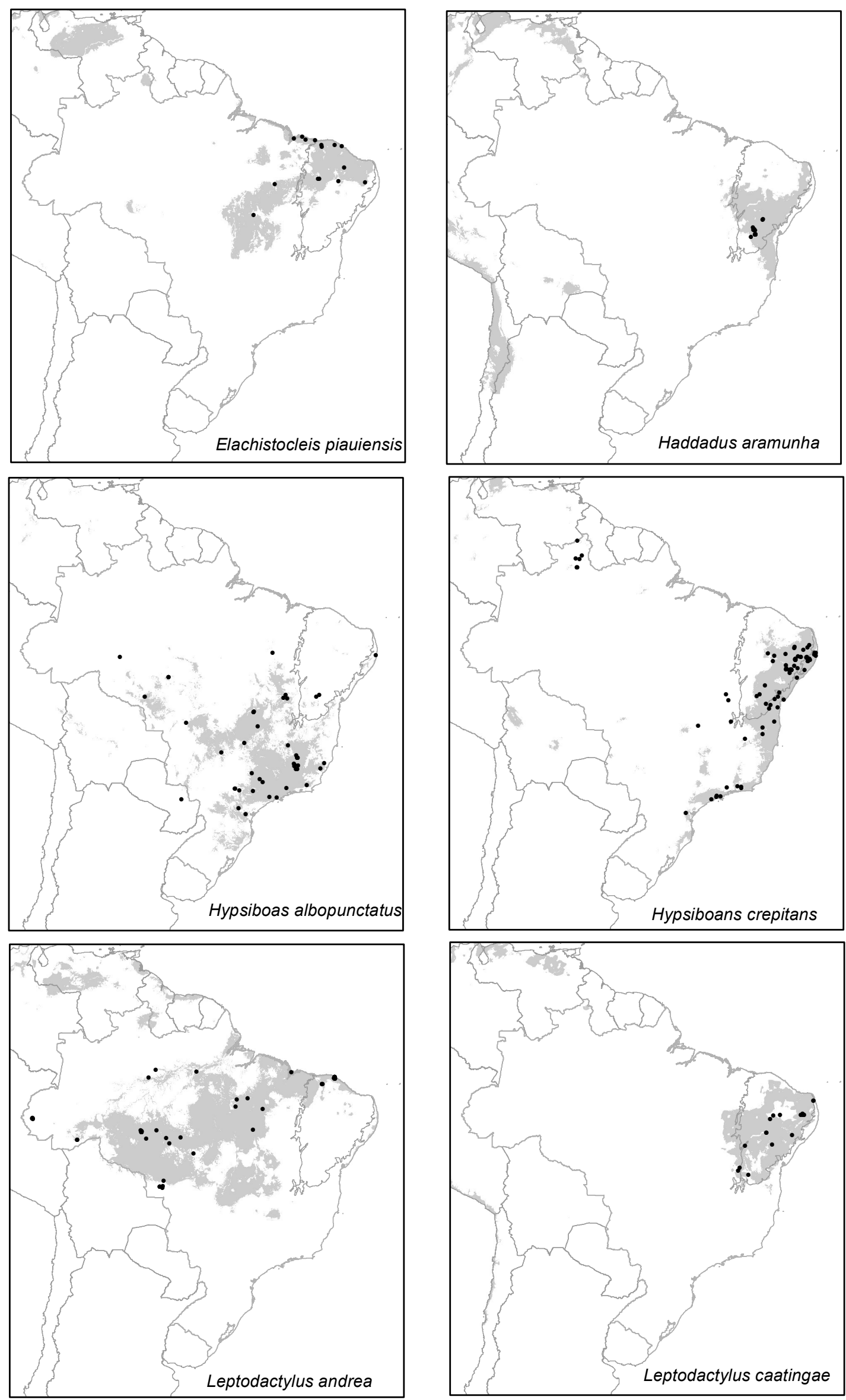

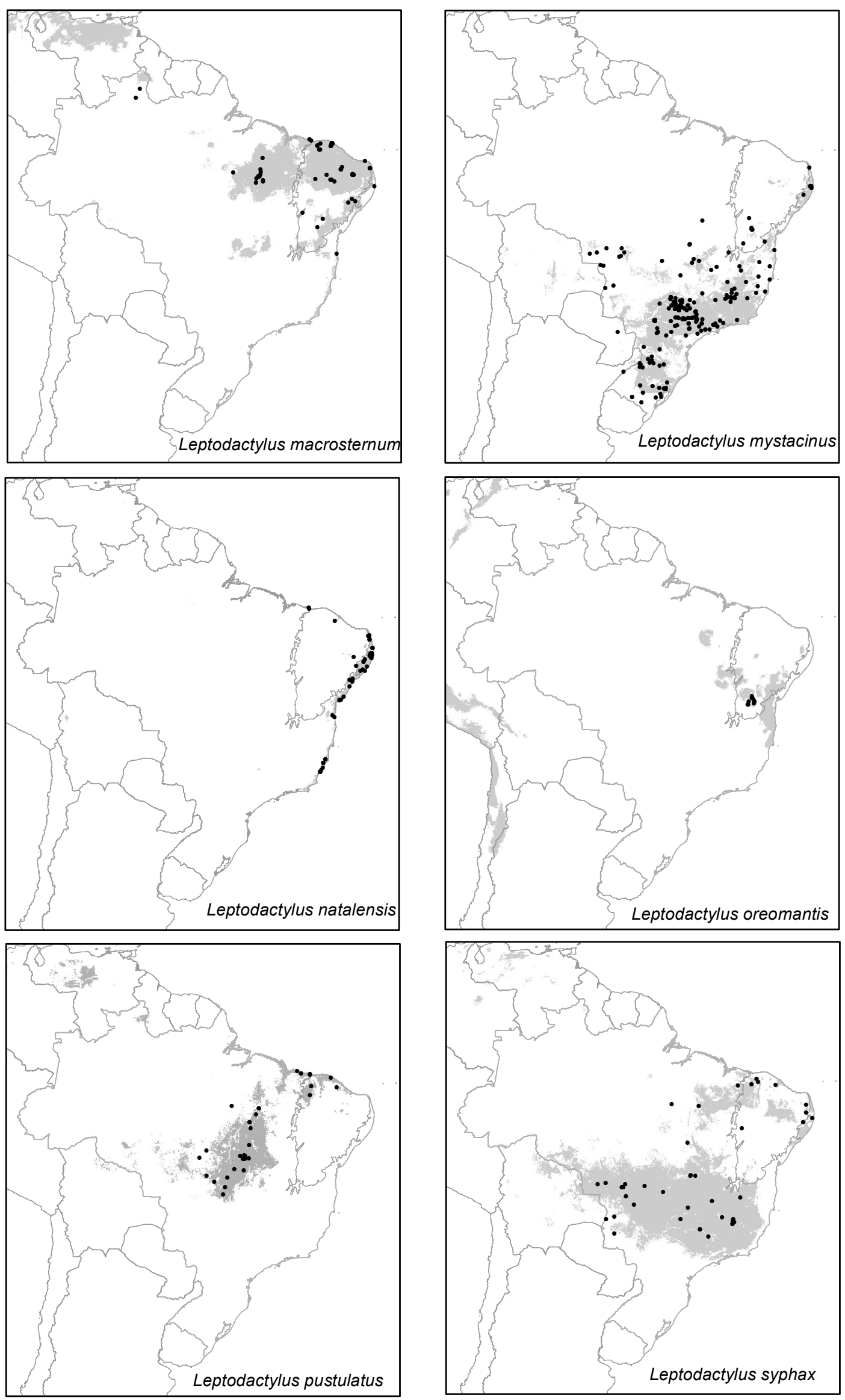

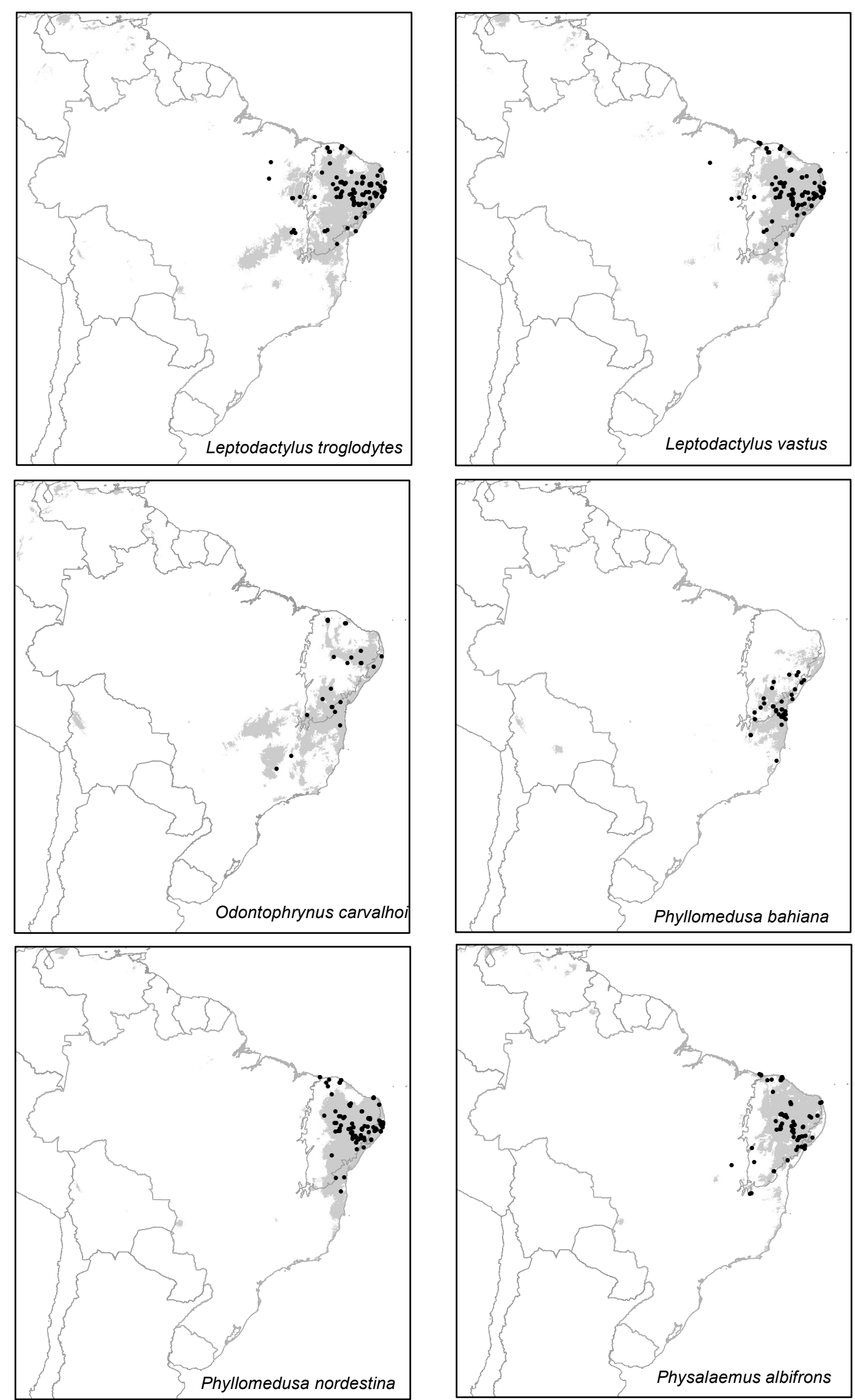

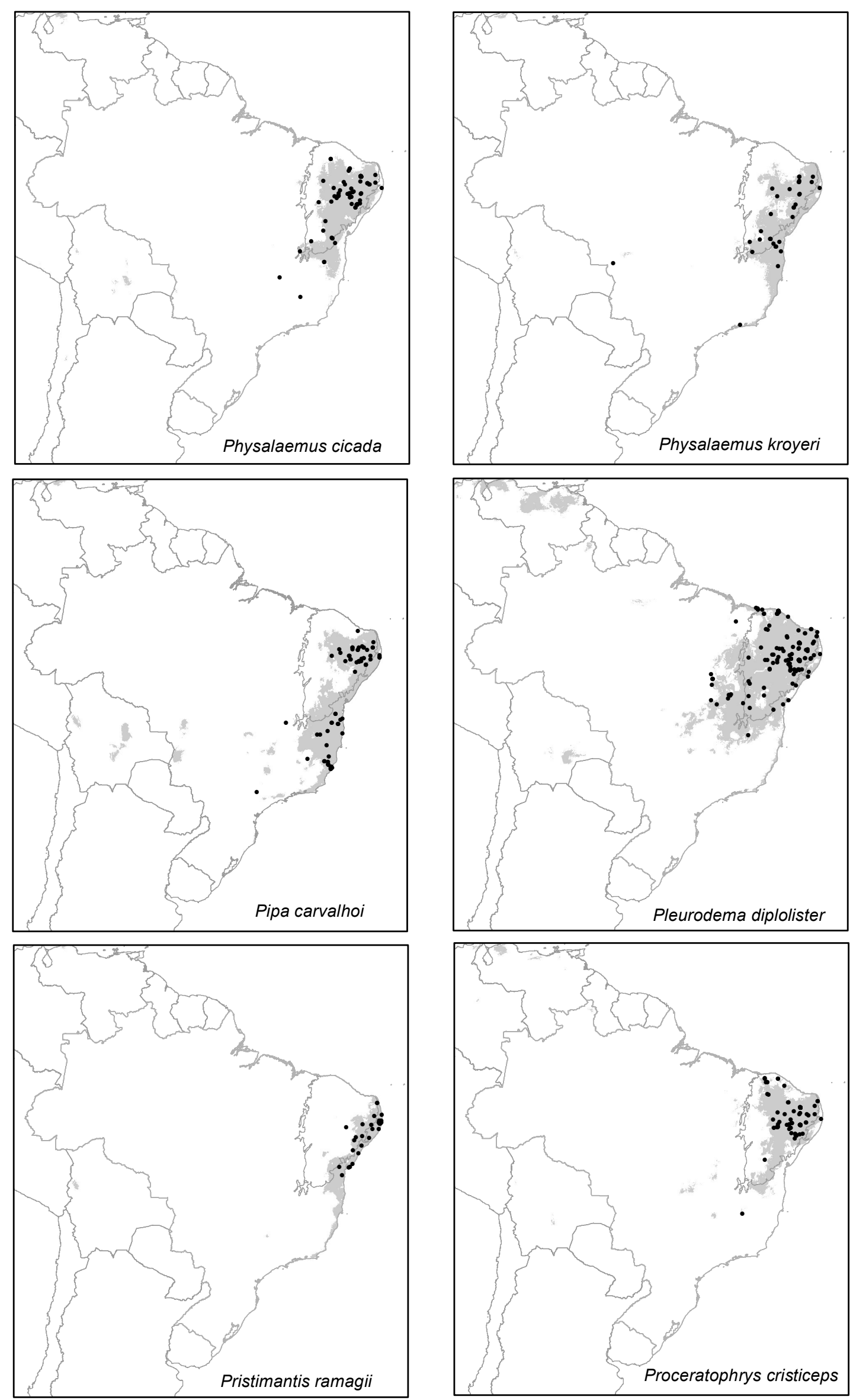

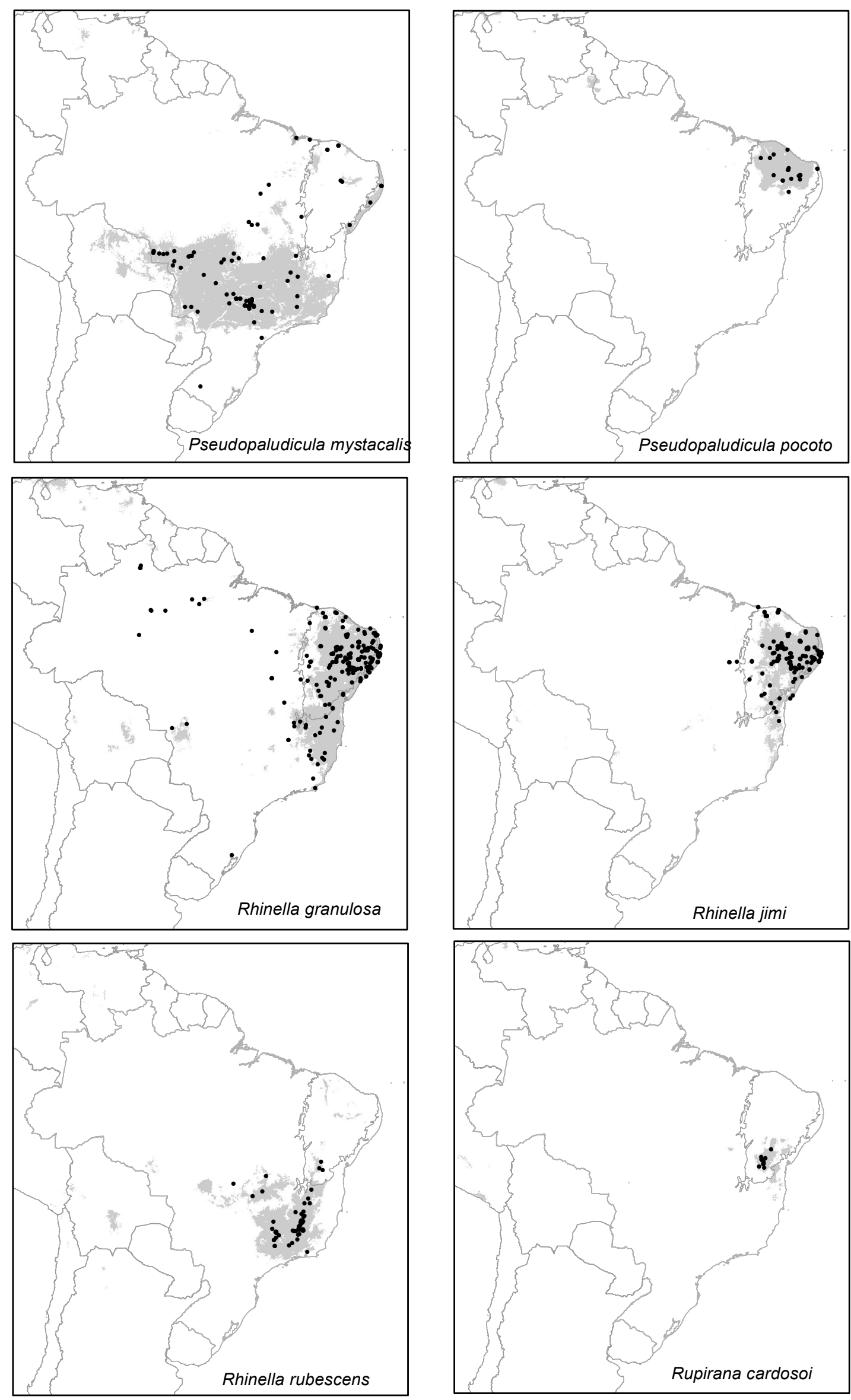

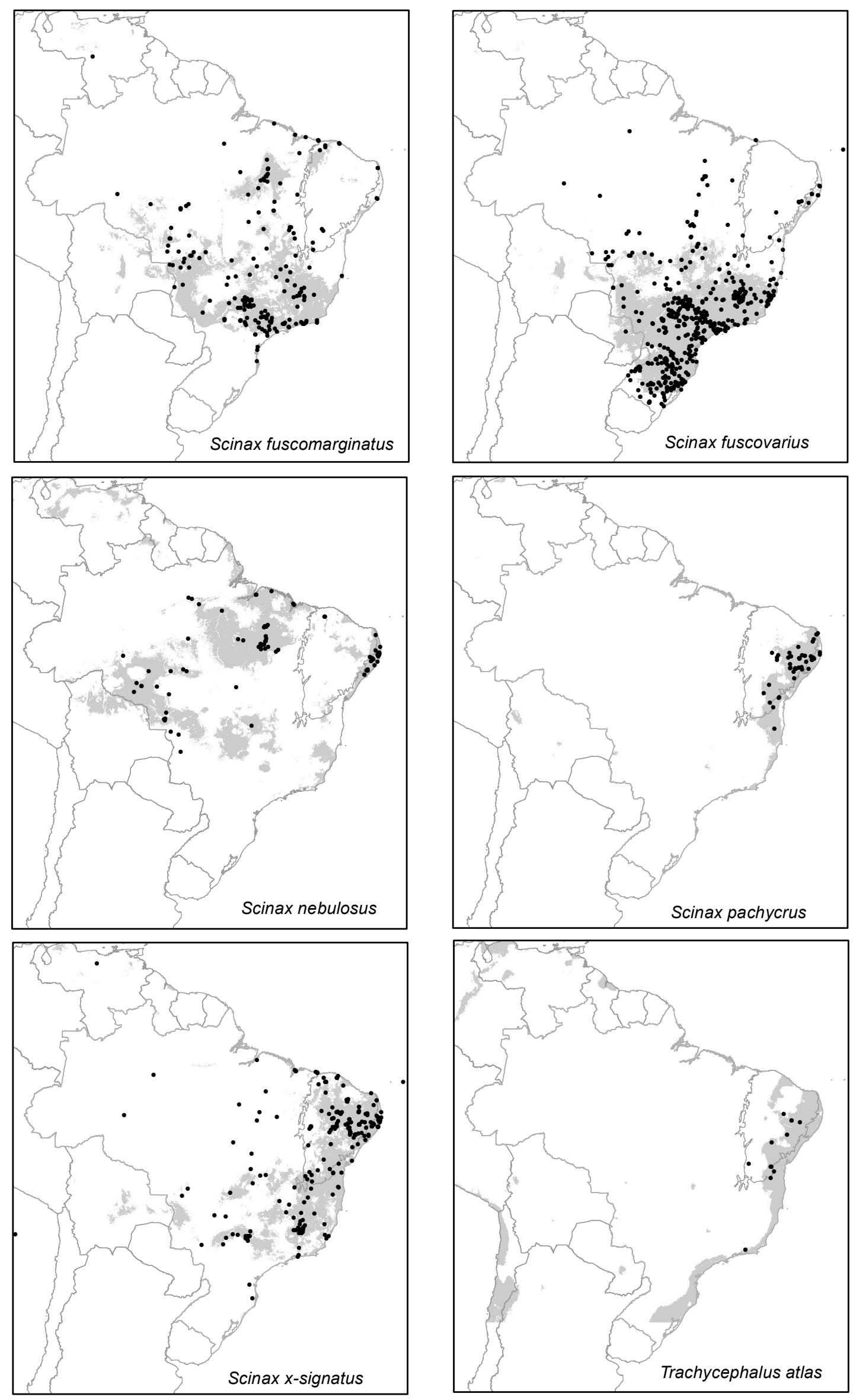
Tabela S2. Espécies selecionadas para análise de endemicidade e a relação dos pontos obtidos nos limites da Caatinga.

\begin{tabular}{|c|c|c|c|c|}
\hline Espécie & Distribuição & $\begin{array}{l}\text { Pontos } \\
\text { Totais }\end{array}$ & $\begin{array}{l}\text { Pontos na } \\
\text { Caatinga }\end{array}$ & $\begin{array}{c}\% \\
\text { Caatinga }\end{array}$ \\
\hline Bokermannohyla diamantina & Restrita & 7 & 7 & $100 \%$ \\
\hline Bokermannohyla itapoty & Restrita & 13 & 13 & $100 \%$ \\
\hline Bokermannohyla juiju & Restrita & 2 & 2 & $100 \%$ \\
\hline Bokermannohyla oxente & Restrita & 23 & 23 & $100 \%$ \\
\hline Ceratophrys joazeirensis & Restrita & 12 & 10 & $83 \%$ \\
\hline Corythomantis galeata & Restrita & 1 & 1 & $100 \%$ \\
\hline Corythomantis greeningi & Restrita & 91 & 72 & $79 \%$ \\
\hline Dendropsophus branneri & Restrita & 61 & 25 & $41 \%$ \\
\hline Dendropsophus novaisi & Restrita & 7 & 7 & $100 \%$ \\
\hline Dendropsophus oliveirai & Restrita & 28 & 13 & $46 \%$ \\
\hline Dendropsophus soaresi & Restrita & 50 & 26 & $52 \%$ \\
\hline Dermatonotus muelleri & Ampla & 73 & 43 & $59 \%$ \\
\hline Elachistocleis piauiensis & Restrita & 15 & 8 & $53 \%$ \\
\hline Haddadus aramunha & Restrita & 13 & 13 & $100 \%$ \\
\hline Hypsiboas crepitans & Ampla & 81 & 36 & $44 \%$ \\
\hline Leptodactylus caatingae & Restrita & 16 & 16 & $100 \%$ \\
\hline Leptodactylus macrosternum & Ampla & 50 & 28 & $56 \%$ \\
\hline Leptodactylus oreomantis & Restrita & 9 & 9 & $100 \%$ \\
\hline Leptodactylus troglodytes & Restrita & 113 & 83 & $73 \%$ \\
\hline Leptodactylus vastus & Restrita & 102 & 63 & $62 \%$ \\
\hline Odontophrynus carvalhoi & Restrita & 26 & 16 & $62 \%$ \\
\hline Phyllodytes acuminatus & Restrita & 8 & 8 & $100 \%$ \\
\hline Phyllomedusa bahiana & Restrita & 34 & 12 & $35 \%$ \\
\hline Phyllomedusa nordestina & Restrita & 99 & 67 & $68 \%$ \\
\hline Physalaemus albifrons & Restrita & 64 & 50 & $78 \%$ \\
\hline Physalaemus cicada & Restrita & 59 & 50 & $85 \%$ \\
\hline Physalaemus kroyeri & Restrita & 29 & 19 & $66 \%$ \\
\hline Pipa carvalhoi & Ampla & 64 & 34 & $53 \%$ \\
\hline Pleurodema alium & Restrita & 3 & 3 & $100 \%$ \\
\hline Pleurodema diplolister & Restrita & 112 & 84 & $75 \%$ \\
\hline Pristimantis ramagii & Restrita & 31 & 11 & $35 \%$ \\
\hline Proceratophrys aridus & Restrita & 6 & 6 & $100 \%$ \\
\hline
\end{tabular}


Tabela S2 (Cont.). Espécies selecionadas para análise de endemicidade e a relação dos pontos obtidos nos limites da Caatinga.

\begin{tabular}{lcccc} 
Proceratophrys caramaschii & Restrita & 3 & 3 & $100 \%$ \\
Proceratophrys cristiceps & Restrita & 61 & 58 & $95 \%$ \\
Proceratophrys minuta & Restrita & 4 & 4 & $100 \%$ \\
Pseudopaludicola pocoto & Restrita & 18 & 18 & $100 \%$ \\
Rhinella granulosa & Ampla & 218 & 133 & $61 \%$ \\
Rhinella jimi & Restrita & 126 & 85 & $67 \%$ \\
Rupirana cardosoi & Restrita & 16 & 16 & $100 \%$ \\
Scinax camposseabrai & Restrita & 8 & 8 & $100 \%$ \\
Scinax pachycrus & Restrita & 50 & 36 & $72 \%$ \\
Scinax x-signatus & Ampla & 207 & 91 & $44 \%$ \\
Trachycephalus atlas & Restrita & 12 & 7 & $58 \%$ \\
\hline
\end{tabular}
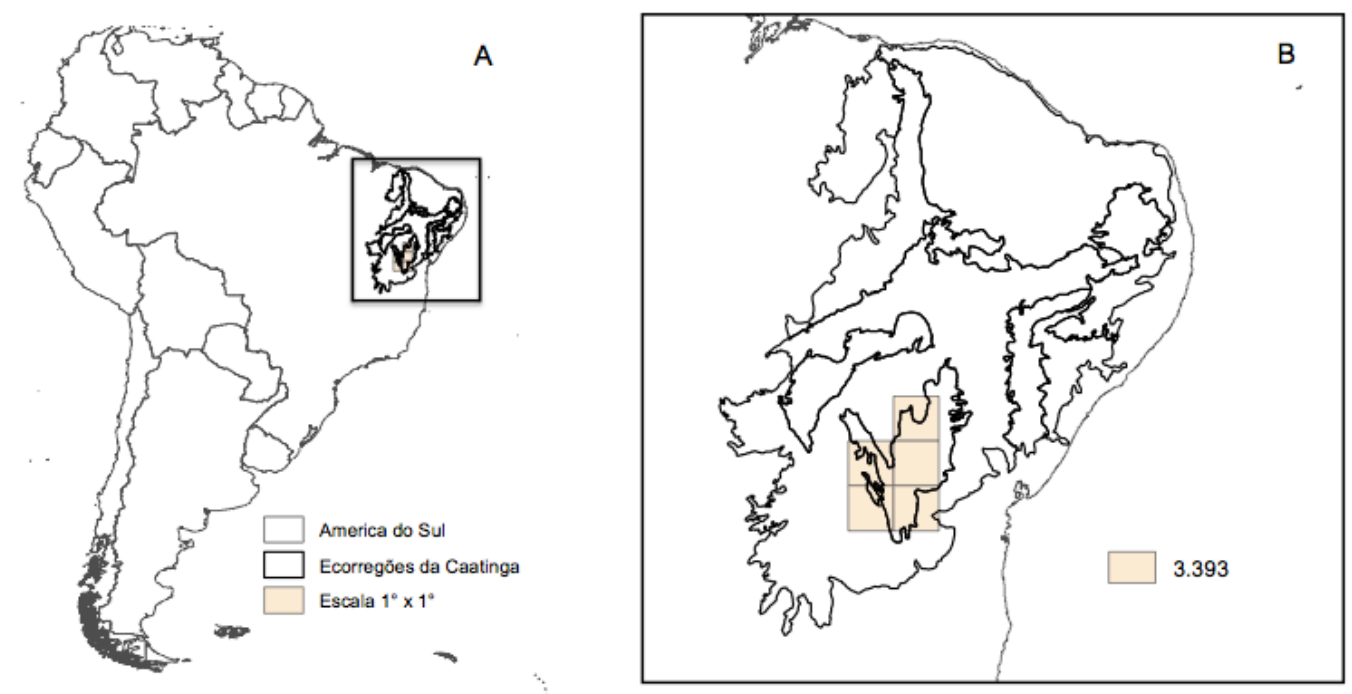

Figura S2. (A) Mapa da América do Sul e as ecorregiões da Caatinga. (B) Destaque das ecorregiões da Caatinga e área de endemismo obtida para quadrículas $1^{\circ} \times 1^{\circ}$. 
Tabela S3. Espécies representantes das áreas consenso obtidas nas diferentes escalas $2^{\circ} \times 2^{\circ}, 3^{\circ} \times 3^{\circ}, 4^{\circ} \times 4^{\circ}$ e $5^{\circ} \times 5^{\circ}$.

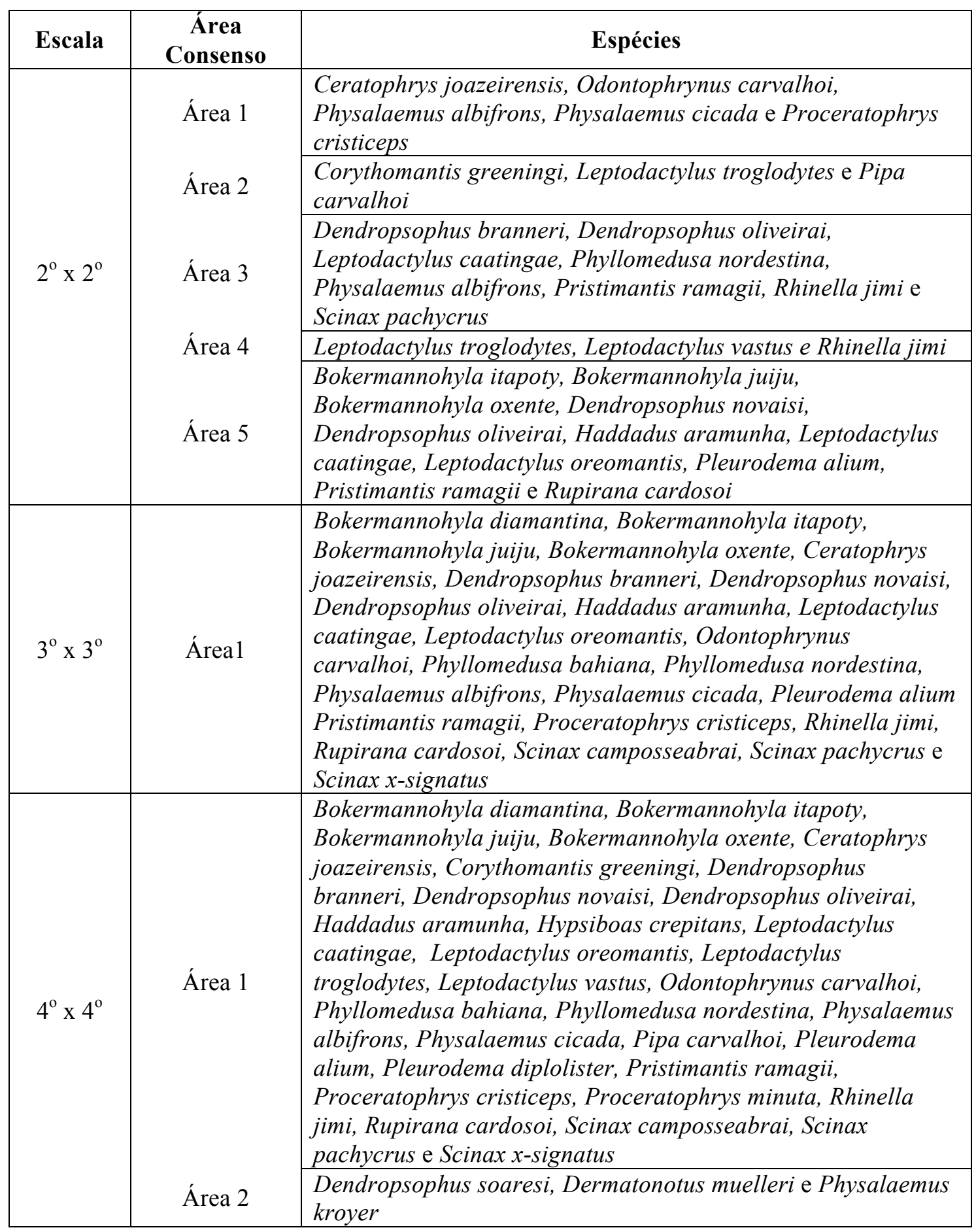


Tabela S3 (Cont.). Espécies representantes das áreas consenso obtidas nas escalas $2^{\circ}$ $\times 2^{\circ}, 3^{\circ} \times 3^{\circ}, 4^{\circ} \times 4^{\circ}$ e $5^{\circ} \times 5^{\circ}$.

\begin{tabular}{|c|c|c|}
\hline \multirow{6}{*}{$5^{\circ} \times 5^{\circ}$} & \multirow{2}{*}{$\begin{array}{l}\text { Área } 1 \\
\text { Área } 2\end{array}$} & $\begin{array}{l}\text { Bokermannohyla diamantina, Bokermannohyla itapoty, } \\
\text { Bokermannohyla juiju, Bokermannohyla oxente, Ceratophrys } \\
\text { joazeirensis, Corythomantis greeningi, Dendropsophus } \\
\text { branneri, Dendropsophus novaisi, Dendropsophus oliveirai, } \\
\text { Dendropsophus soaresi, Haddadus aramunha, Leptodactylus } \\
\text { caatingae, Leptodactylus troglodytes, Leptodactylus vastus, } \\
\text { Odontophrynus carvalhoi, Phyllomedusa bahiana, } \\
\text { Physalaemus albifrons, Physalaemus cicada, Pipa carvalhoi, } \\
\text { Pleurodema diplolister, Proceratophrys cristiceps, } \\
\text { Proceratophrys minuta, Rhinella jimi, Rupirana cardosoi, } \\
\text { Scinax camposseabrai, Scinax pachycrus e Scinax x-signatus }\end{array}$ \\
\hline & & $\begin{array}{l}\text { Bokermannohyla itapoty, Bokermannohyla oxente, } \\
\text { Ceratophrys joazeirensis, Dendropsophus branneri, } \\
\text { Dendropsophus novaisi, Dendropsophus oliveirai, } \\
\text { Elachistocleis piauiensis, Haddadus aramunha, Leptodactylus } \\
\text { caatingae, Leptodactylus vastus, Phyllomedusa bahiana, } \\
\text { Phyllomedusa nordestina, Physalaemus albifrons, } \\
\text { Physalaemus cicada,Pleurodama diplolister, Proceratophrys } \\
\text { cristiceps, Proceratophrys minuta, Pseudopaludicola pocoto, } \\
\text { Rhinella jimi, Rupirana cardosoi, Scinax camposseabrai, } \\
\text { Scinax pachycrus e Scinax x-signatus }\end{array}$ \\
\hline & Área 3 & $\begin{array}{l}\text { Bokermannohyla itapoty, Bokermannohyla oxente, } \\
\text { Ceratophrys joazeirensis, Corythomantis greeningi, } \\
\text { Dendropsophus branneri, Dendropsophus novaisi, } \\
\text { Dendropsophus oliveirai, Elachistocleis piauiensis, Haddadus } \\
\text { aramunha, Leptodactylus caatingae, Leptodactylus } \\
\text { troglodytes, Leptodactylus vastus, Odontophrynus carvalhoi, } \\
\text { Phyllomedusa bahiana, Physalaemus albifrons, Physalaemus } \\
\text { cicada, Pipa carvalhoi, Pleurodema diplolister, } \\
\text { Proceratophrys cristiceps, Proceratophrys minuta, Rhinella } \\
\text { jimi, Rupirana cardosoi, Scinax camposseabrai, Scinax } \\
\text { pachycrus e Scinax x-signatus }\end{array}$ \\
\hline & Área 4 & $\begin{array}{l}\text { Bokermannohyla diamantina, Bokermannohyla oxente, } \\
\text { Ceratophrys joazeirensis, Corythomantis greeningi, } \\
\text { Dendropsophus branneri, Dendropsophus novaisi, } \\
\text { Dendropsophus oliveirai, Dendropsophus soaresi, Haddadus } \\
\text { aramunha, Leptodactylus caatingae, Leptodactylus } \\
\text { troglodytes, Leptodactylus vastus, Odontophrynus carvalhoi, } \\
\text { Phyllomedusa bahiana, Physalaemus albifrons, Physalaemus } \\
\text { cicada, Pipa carvalhoi, Pleurodema diplolister, } \\
\text { Proceratophrys caramaschi, Proceratophrys cristiceps, } \\
\text { Proceratophrys minuta, Rhinella jimi, Rupirana cardosoi, } \\
\text { Scinax camposseabrai, Scinax pachycrus e Scinax x-signatus }\end{array}$ \\
\hline & Área 5 & $\begin{array}{l}\text { Dendropsophus soaresi, Dermatonotus muelleri e } \\
\text { Physalaemus kroyer }\end{array}$ \\
\hline & Área 6 & $\begin{array}{l}\text { Hypsiboas crepitans, Leptodactylus macrosternum e Rhinella } \\
\text { granulosa }\end{array}$ \\
\hline
\end{tabular}



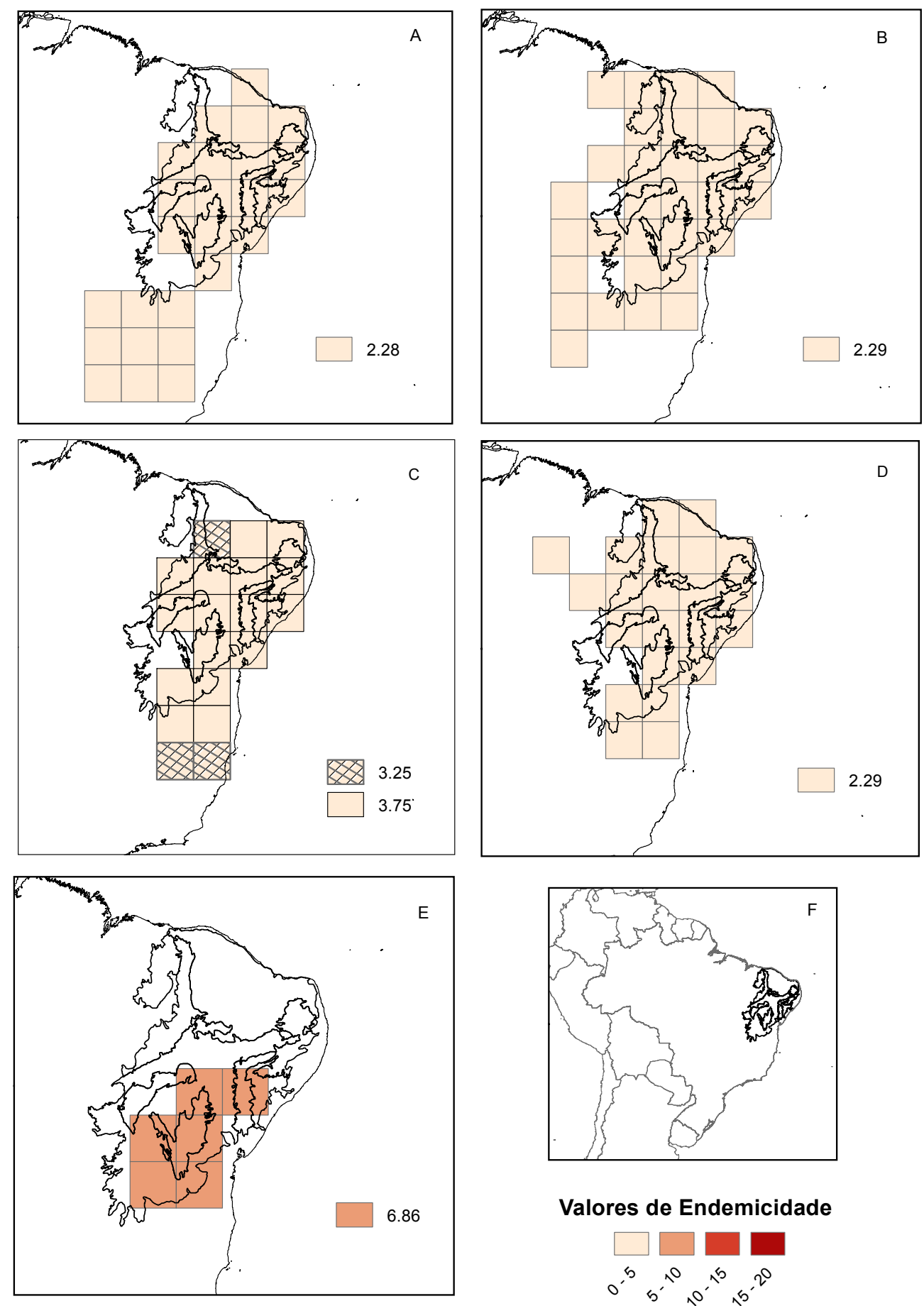

Figura S3. Áreas de endemismo obtidas com quadrículas $2^{\circ} \times 2^{\circ}$. Destaque das ecorregiões da Caatinga mostrando: (A) área consenso 1; (B) área consenso 2; (C) área consenso 3; (D) área consenso 4 e (E) área consenso 5. Os limites das ecorregiões inseridos no mapa do Brasil. 

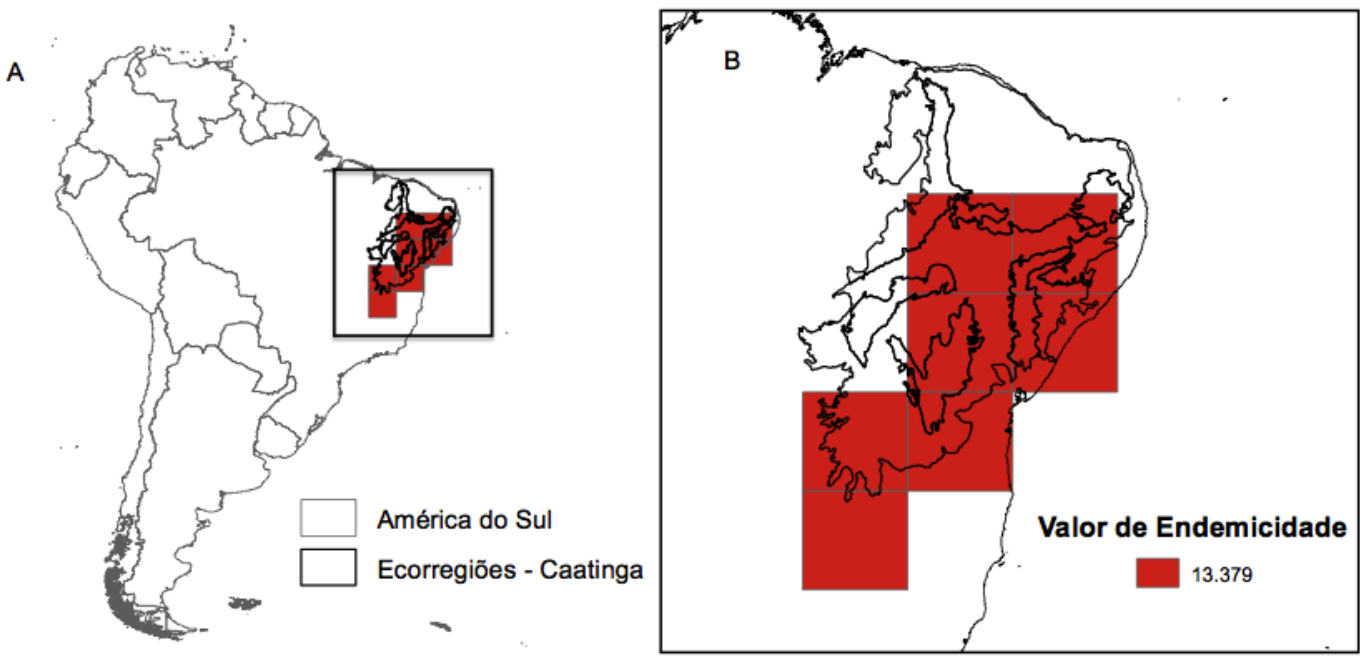

Figura S4. Área consenso de endemismo obtida com quadrículas na escala $3^{\circ} \times 3^{\circ}$. (A) Área de endemismo nos limites da América do Sul e ecorregiões da Caatinga; (B) Destaque da área consenso e os limites das ecorregiões da Caatinga.

A

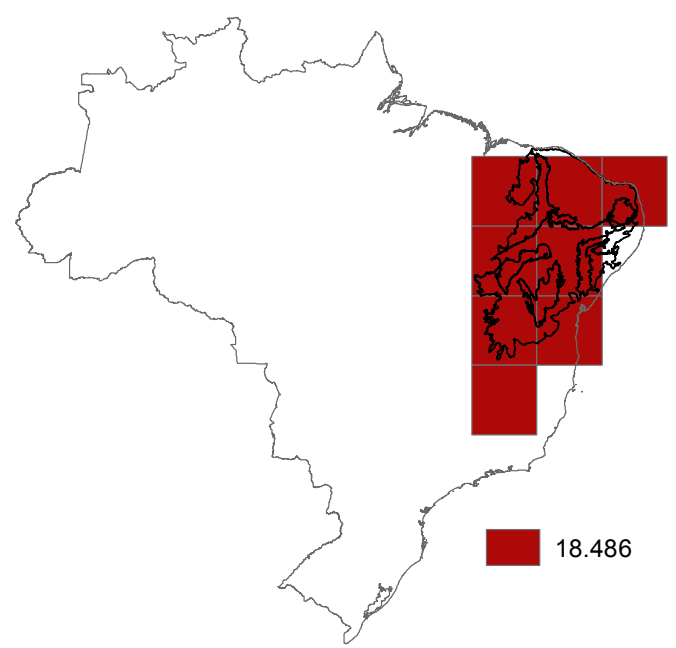

B

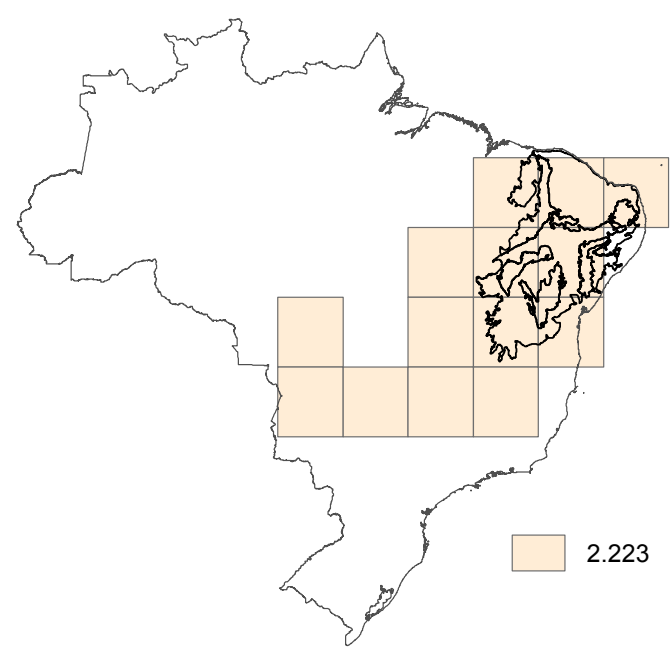

Valores de Endemicidade

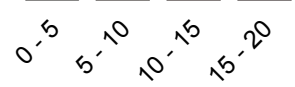

Figura S5. Áreas de endemismo consenso obtidas para quadrículas $4^{\circ} \times 4^{\circ}$. (A) Área consenso 1 e (B) área consenso 2. 

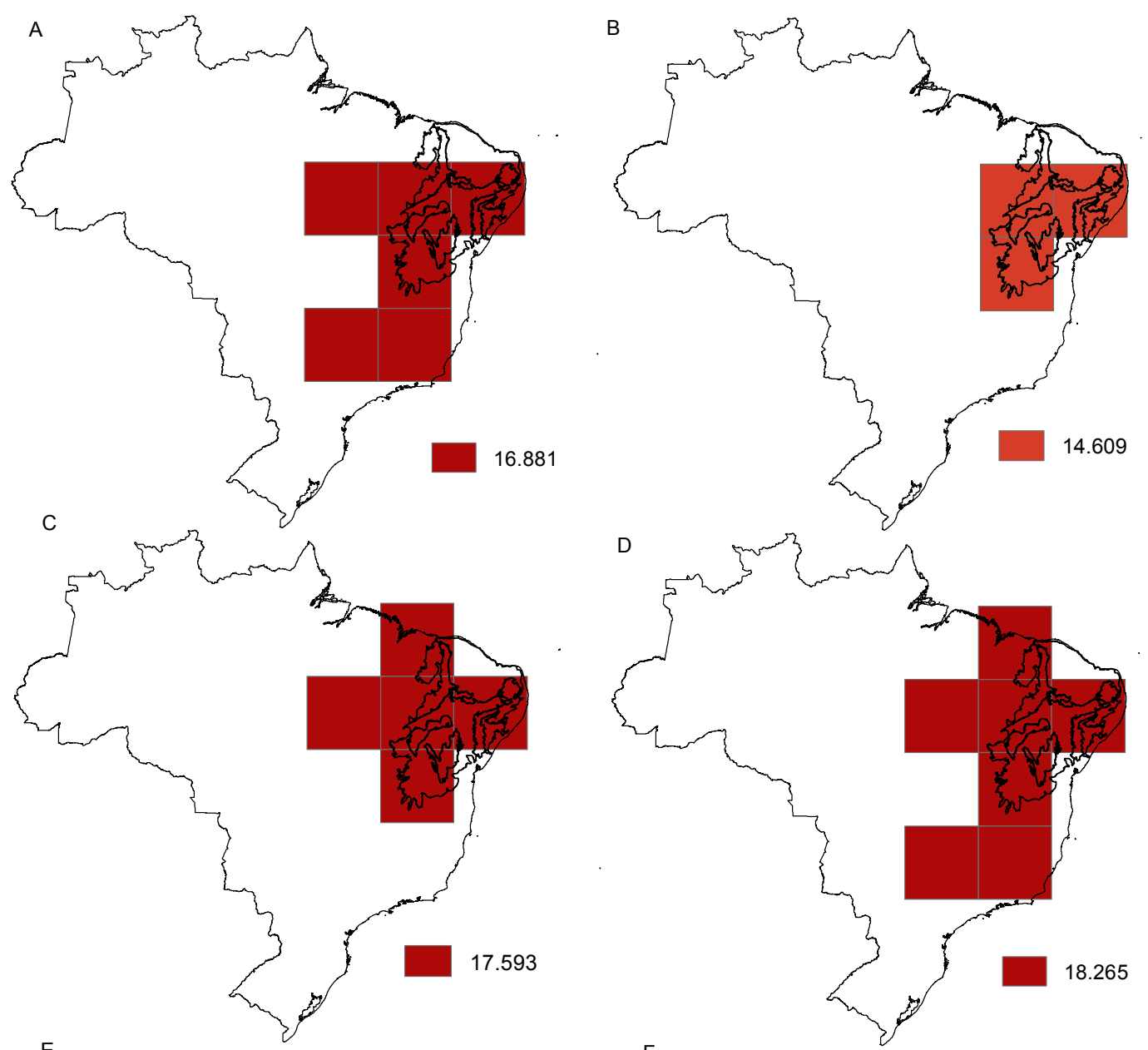

$\mathrm{E}$
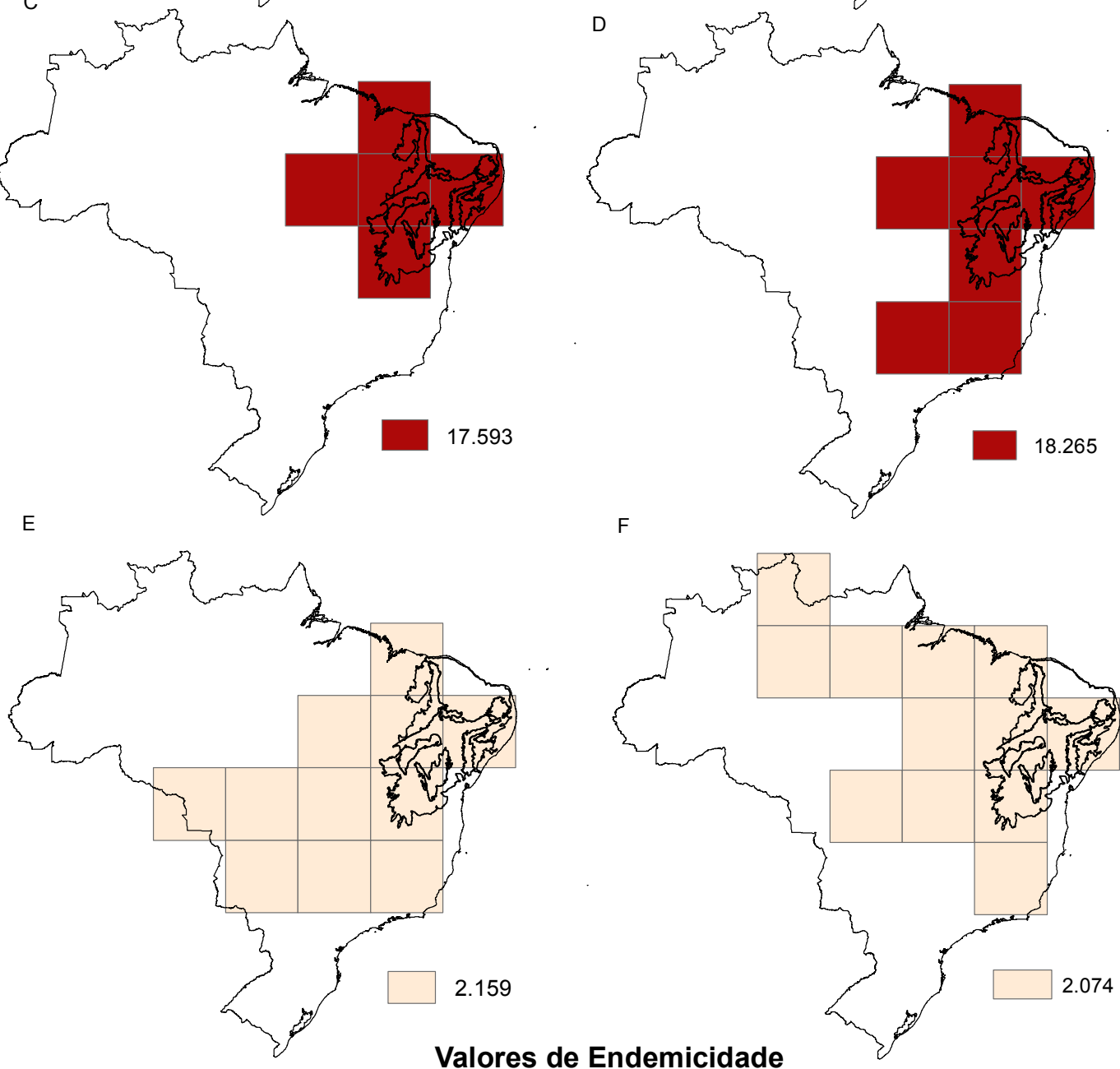

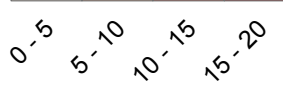

Figura S6. Áreas de endemismo obtidas com quadrículas $5^{\circ} \times 5^{\circ}$, inseridas nos limites do território brasileiro e nas ecorregiões da Caatinga. (A) Área consenso 1; (B) área consenso 2; (C) área consenso 3; (D) área consenso 4; (E) área consenso 5 e (F) área consenso 6 . 
Tabela S3. A relação das espécies como indicadores de um dos grupos identificados para Caatinga, as espécies em negrito representam as espécies estatisticamente significantes como indicadoras de um dos grupos. Frequência das espécies nos grupos Campo Maior (CM), Sul (SU), Oeste (OE), Diamantina (DI), Centro-Leste (CL) e Norte (NO). O grupo no qual a espécie mostrou maior valor de associação (Grupo Max), índice de associação da espécie ao grupo de maior valor de associação (IndA) e significância da relação da espécie com o grupo (p).

\begin{tabular}{|c|c|c|c|c|c|c|c|c|c|}
\hline \multirow{2}{*}{ Espécie } & \multirow{2}{*}{$\begin{array}{c}\text { Grupo } \\
\text { Max }\end{array}$} & \multirow{2}{*}{ Ind A } & \multirow{2}{*}{$\mathbf{p}$} & \multicolumn{6}{|c|}{ Frequência nos Grupos } \\
\hline & & & & $\mathbf{C M}$ & SU & $\mathbf{O E}$ & DI & $\mathbf{C L}$ & NO \\
\hline Bokermannohyla diamantina & $\mathrm{CL}$ & 0.072 & 0.272 & 0.00 & 0.00 & 0.00 & 0.00 & 0.07 & 0.00 \\
\hline Bokermannohyla itapoty & DI & 0.322 & 0.003 & 0.09 & 0.44 & 0.94 & 1.00 & 0.38 & 0.26 \\
\hline Bokermannohyla oxente & $\mathrm{CL}$ & 0.098 & 0.284 & 0.00 & 0.00 & 0.00 & 0.00 & 0.10 & 0.00 \\
\hline Ceratophrys joazeirensis & $\mathrm{CM}$ & 0.167 & 1 & 1.00 & 1.00 & 1.00 & 1.00 & 0.97 & 1.00 \\
\hline Corythomantis greeningi & NO & 0.195 & 0.346 & 0.82 & 0.78 & 0.64 & 0.25 & 0.64 & 0.89 \\
\hline Dendropsophus branneri & SU & 0.228 & 0.06 & 0.09 & 0.78 & 0.44 & 0.25 & 0.38 & 0.71 \\
\hline Dendropsophus decipiens & SU & 0.176 & 0.115 & 0.00 & 0.44 & 0.16 & 0.25 & 0.10 & 0.17 \\
\hline Dendropsophus elegans & DI & 0.099 & 0.228 & 0.00 & 0.22 & 0.00 & 0.25 & 0.01 & 0.14 \\
\hline Dendropsophus minutus & NO & 0.153 & 0.168 & 0.09 & 0.11 & 0.02 & 0.25 & 0.18 & 0.40 \\
\hline Dendropsophus nanus & $\mathbf{S U}$ & 0.192 & 0.008 & 0.27 & 1.00 & 1.00 & 1.00 & 0.96 & 0.97 \\
\hline Dendropsophus novaisi & $\mathrm{CL}$ & 0.011 & 1 & 0.00 & 0.00 & 0.02 & 0.00 & 0.02 & 0.00 \\
\hline Dendropsophus oliveirai & $\mathrm{OE}$ & 0.064 & 0.785 & 0.00 & 0.22 & 0.27 & 0.25 & 0.22 & 0.14 \\
\hline Dendropsophus rubicundulus & $\mathbf{C M}$ & 0.341 & 0.01 & 0.64 & 0.00 & 0.02 & 0.25 & 0.20 & 0.09 \\
\hline Dendropsophus soaresi & NO & 0.206 & 0.272 & 0.36 & 0.78 & 0.58 & 0.25 & 0.73 & 0.86 \\
\hline Dermatonotus muelleri & NO & 0.205 & 0.006 & 0.64 & 0.78 & 0.78 & 0.50 & 0.93 & 0.97 \\
\hline Elachistocleis piauiensis & $\mathbf{C M}$ & 0.305 & 0.028 & 0.91 & 0.22 & 0.16 & 0.25 & 0.43 & 0.74 \\
\hline Haddadus aramunha & OE & 0.304 & 0.007 & 0.09 & 0.56 & 0.97 & 0.75 & 0.38 & 0.34 \\
\hline Hypsiboas albopunctatus & DI & 0.177 & 0.041 & 0.00 & 0.00 & 0.02 & 0.25 & 0.09 & 0.00 \\
\hline Hypsiboas crepitans & SU & 0.211 & 0.089 & 0.09 & 0.78 & 0.56 & 0.25 & 0.40 & 0.77 \\
\hline Hypsiboas punctatus & $\mathrm{CM}$ & 0.166 & 1 & 1.00 & 1.00 & 1.00 & 1.00 & 1.00 & 1.00 \\
\hline Hypsiboas raniceps & DI & 0.25 & 0.093 & 0.45 & 0.78 & 0.66 & 1.00 & 0.50 & 0.60 \\
\hline Leptodactylus andreae & $\mathbf{C M}$ & 0.661 & 0.001 & 0.82 & 0.00 & 0.00 & 0.00 & 0.16 & $\mathbf{0 . 0 3}$ \\
\hline Leptodactylus caatingae & SU & 0.206 & 0.063 & 0.27 & 1.00 & 0.98 & 1.00 & 0.78 & 0.80 \\
\hline Leptodactylus fuscus & $\mathrm{CM}$ & 0.166 & 1 & 1.00 & 1.00 & 1.00 & 1.00 & 1.00 & 1.00 \\
\hline Leptodactylus macrosternum & $\mathbf{C M}$ & 0.247 & 0.029 & 1.00 & 0.78 & 0.34 & 0.25 & 0.70 & 0.97 \\
\hline Leptodactylus mystaceus & NO & 0.138 & 0.072 & 0.09 & 0.11 & 0.06 & 0.00 & 0.04 & 0.29 \\
\hline Leptodactylus mystacinus & $\mathrm{NO}$ & 0.152 & 0.053 & 0.00 & 0.00 & 0.02 & 0.00 & 0.05 & 0.20 \\
\hline Leptodactylus natalensis & SU & 0.051 & 0.388 & 0.00 & 0.11 & 0.02 & 0.00 & 0.03 & 0.09 \\
\hline Leptodactylus oreomantis & DI & 0.215 & 0.056 & 0.00 & 0.00 & 0.31 & 0.50 & 0.29 & 0.06 \\
\hline Leptodactylus pustulatus & $\mathbf{C M}$ & 0.804 & 0.001 & 0.91 & 0.00 & 0.00 & 0.00 & 0.12 & 0.00 \\
\hline Leptodactylus syphax & NO & 0.153 & 0.17 & 0.45 & 0.44 & 0.02 & 0.00 & 0.29 & 0.51 \\
\hline Leptodactylus troglodytes & NO & 0.213 & 0.039 & 0.55 & 0.78 & 0.86 & 0.25 & 0.79 & 0.94 \\
\hline
\end{tabular}


Tabela S3 (Cont.). A relação das espécies como indicadores de um dos grupos identificados para Caatinga, as espécies em negrito representam as espécies estatisticamente significantes como indicadoras de um dos grupos. Frequência das espécies nos grupos Campo Maior (CM), Sul (SU), Oeste (OE), Diamantina (DI), Centro-Leste (CL) e Norte (NO). O grupo no qual a espécie mostrou maior valor de associação (Grupo Max), índice de associação da espécie ao grupo de maior valor de associação (IndA) e significância da relação da espécie com o grupo (p).

\begin{tabular}{|c|c|c|c|c|c|c|c|c|c|}
\hline Leptodactylus vastus & NO & 0.195 & 0.302 & 0.55 & 0.78 & 0.69 & 0.25 & 0.63 & 0.86 \\
\hline Odontophrynus carvalhoi & NO & 0.237 & 0.072 & 0.18 & 0.67 & 0.23 & 0.25 & 0.57 & 0.80 \\
\hline Phyllodytes acuminatus & DI & 0.162 & 0.084 & 0.00 & 0.00 & 0.09 & 0.25 & 0.01 & 0.03 \\
\hline Phyllomedusa bahiana & SU & 0.121 & 0.443 & 0.00 & 0.44 & 0.28 & 0.25 & 0.24 & 0.40 \\
\hline Phyllomedusa nordestina & NO & 0.22 & 0.159 & 0.45 & 0.78 & 0.66 & 0.25 & 0.54 & 0.89 \\
\hline Physalaemus albifrons & NO & 0.185 & 0.413 & 0.91 & 0.78 & 0.78 & 0.50 & 0.61 & 0.91 \\
\hline Physalaemus centralis & CL & 0.019 & 0.554 & 0.00 & 0.00 & 0.00 & 0.00 & 0.02 & 0.00 \\
\hline Physalaemus cicada & NO & 0.246 & 0.05 & 0.09 & 0.78 & 0.78 & 0.25 & 0.57 & 0.91 \\
\hline Physalaemus cuvieri & $\mathrm{CM}$ & 0.166 & 1 & 1.00 & 1.00 & 1.00 & 1.00 & 1.00 & 1.00 \\
\hline Physalaemus kroyeri & NO & 0.231 & 0.102 & 0.09 & 0.78 & 0.55 & 0.25 & 0.47 & 0.83 \\
\hline Pipa carvalhoi & NO & 0.244 & 0.063 & 0.09 & 0.78 & 0.36 & 0.25 & 0.50 & 0.83 \\
\hline Pleurodema alium & CL & 0.039 & 0.496 & 0.00 & 0.00 & 0.00 & 0.00 & 0.04 & 0.00 \\
\hline Pleurodema diplolister & $\mathrm{CM}$ & 0.169 & 1 & 1.00 & 1.00 & 0.98 & 1.00 & 0.91 & 1.00 \\
\hline Pristimantis ramagii & SU & 0.142 & 0.247 & 0.00 & 0.44 & 0.19 & 0.25 & 0.13 & 0.37 \\
\hline Proceratophrys aridus & NO & 0.057 & 0.177 & 0.00 & 0.00 & 0.00 & 0.00 & 0.00 & 0.06 \\
\hline Proceratophrys cristiceps & NO & 0.202 & 0.239 & 0.55 & 0.78 & 0.61 & 0.25 & 0.59 & 0.86 \\
\hline Proceratophrys minuta & $\mathrm{CL}$ & 0.013 & 0.735 & 0.00 & 0.00 & 0.00 & 0.00 & 0.01 & 0.00 \\
\hline Pseudopaludicola mystacalis & $\mathrm{NO}$ & 0.12 & 0.136 & 0.27 & 0.00 & 0.00 & 0.00 & 0.12 & 0.29 \\
\hline Pseudopaludicola pocoto & $\mathbf{C M}$ & 0.307 & 0.024 & 0.91 & 0.56 & 0.05 & 0.00 & 0.40 & 0.77 \\
\hline Rhinella granulosa & NO & 0.171 & 0.702 & 0.82 & 0.78 & 0.83 & 0.75 & 0.79 & 0.91 \\
\hline Rhinella jimi & NO & 0.209 & 0.215 & 0.55 & 0.78 & 0.75 & 0.25 & 0.53 & 0.89 \\
\hline Rhinella rubescens & CL & 0.043 & 0.724 & 0.09 & 0.00 & 0.00 & 0.00 & 0.12 & 0.11 \\
\hline Rupirana cardosoi & CL & 0.121 & 0.177 & 0.00 & 0.00 & 0.11 & 0.00 & 0.19 & 0.00 \\
\hline Scinax camposseabrai & CL & 0.085 & 0.37 & 0.00 & 0.00 & 0.02 & 0.00 & 0.10 & 0.00 \\
\hline Scinax fuscomarginatus & $\mathbf{C M}$ & 0.339 & 0.005 & 0.45 & 0.00 & 0.00 & 0.00 & 0.13 & 0.03 \\
\hline Scinax fuscovarius & $\mathrm{OE}$ & 0.036 & 0.512 & 0.00 & 0.00 & 0.05 & 0.00 & 0.01 & 0.00 \\
\hline Scinax nebulosus & NO & 0.155 & 0.213 & 0.18 & 0.44 & 0.08 & 0.00 & 0.18 & 0.46 \\
\hline Scinax pachycrus & SU & 0.254 & 0.028 & 0.00 & 0.78 & 0.42 & 0.25 & 0.27 & 0.66 \\
\hline Scinax x.signatus & NO & 0.2 & 0.398 & 0.45 & 0.78 & 0.78 & 0.50 & 0.75 & 0.91 \\
\hline Trachycephalus atlas & SU & 0.232 & 0.059 & 0.18 & 0.78 & 0.41 & 0.25 & 0.39 & 0.60 \\
\hline
\end{tabular}

